Review

\title{
Visualizing Sustainable Supply Chain Management: A Systematic Scientometric Review
}

\author{
Zhiwen Su, Mingyu Zhang * and Wenbing Wu \\ School of Economics and Management, Beijing Jiaotong University, Beijing 100044, China; \\ 19113070@bjtu.edu.cn (Z.S.); wbwu@bjtu.edu.cn (W.W.) \\ * Correspondence: myzhang@bjtu.edu.cn
}

check for updates

Citation: Su, Z.; Zhang, M.; Wu, W. Visualizing Sustainable Supply Chain Management: A Systematic Scientometric Review. Sustainability 2021, 13, 4409. https://doi.org/ $10.3390 /$ su13084409

Academic Editors: Lei Xu, Guo Li, Yi He and Xiaohang Yue

Received: 27 March 2021

Accepted: 13 April 2021

Published: 15 April 2021

Publisher's Note: MDPI stays neutral with regard to jurisdictional claims in published maps and institutional affiliations.

Copyright: (c) 2021 by the authors. Licensee MDPI, Basel, Switzerland. This article is an open access article distributed under the terms and conditions of the Creative Commons Attribution (CC BY) license (https:// creativecommons.org/licenses/by/ $4.0 /)$.

\begin{abstract}
Sustainable supply chain management (SSCM) has been attracting extensive attention from both practitioners and scholars. The main objective of this paper is to visualize and conduct a systematic scientometric review on 9151 articles and reviews published from 2007 to 2021. Research techniques of co-author analysis, co-word analysis, and co-citation analysis are applied to reveal the social structure, conceptual structure, and intellectual structure of the SSCM field, identify main concepts and research hotspots, and illuminate major specialties and emerging trends. The results of this work show that: (1) the top five most productive scholars are Joseph Sarkis, Kannan Govindan, Minglang Tseng, Angappa Gunasekaran, and Charbel Jose Chiappetta Jabbour. The top five most productive institutions are Hong Kong Polytech University, Islamic Azad University, University of Southern Denmark, Dalian University of Technology, and University of Tehran. (2) The main concepts include sustainable supply chain management, green supply chain management, circular economy, corporate social responsibility, and reverse logistics. The research hotspots of the SSCM field, currently, are game theory and circular economy related topics. (3) The leading researchers and influential journals are also identified. The emerging trends include sustainable supplier selection, circular economy, cap-and-trade regulation, blockchain technology, big data analytics, the COVID-19 pandemic, and the best-worst method and logistics performance. Finally, limitations and future researches are discussed. We expect this paper will show a big picture of the SSCM field for researchers as well as practitioners.
\end{abstract}

Keywords: sustainable supply chain management; scientometric review; literature review; CiteSpace

\section{Introduction}

The last decade has witnessed more and more attention from both practitioners and scholars on the sustainable supply chain management (SSCM) domain, which takes environmental, social, and economic outcomes into consideration across a focal firm's supply chain process. More and more enterprises realize the importance of sustainable development and construct sustainable supply chain systems to implement SSCM. To tackle the severe threat and high level of uncertainty due to disasters such as the COVID-19 pandemic [1], demand uncertainty [2,3], a challenging market, combined with pressure from stakeholders (competitors, end-users, or governments, etc.) [4], reputational risk [5], and corporate social responsibility [6], firms make SSCM a strategy so as to ensure long term benefits and achieve a competitive position in the market. SSCM practices, such as adopting green human resource management [7-9], applying environmental management systems [10,11], and evaluating and selecting sustainable suppliers [12-14], are implemented by firms in their internal management and external supply chains' operations.

Therefore, it is no wonder that SSCM has aroused the interest of scholars. The empirical and conceptual papers concerning SSCM topics have been growing significantly, which indicate that SSCM has evolved into a significant separate stream of supply chain management or a new stage of supply chain management, which was believed by the study 
of [15]. In recent years, SSCM scholars have been exploring various scenarios and proposing new findings and designs through scientific studies, such as implications of blockchain technology on SSCM [16,17], approaches and algorithms for sustainable supplier evaluation and selection [18-21], drivers or factor influencing the adoption of SSCM [22-24] and so on, which have contributed significantly to the development and evolution for SSCM research. Indeed, with the development of the SSCM field, there are several closely related concepts paid much attention to by scholars as well, including corporate social responsibility (CSR), green supply chain management (GSCM), responsible supply chain management (RSCM), sustainable procurement (SP), and green procurement (GP). On the one hand, these concepts share some similarities, which put more emphasis on social and environmental obligations and responsibilities. On the other hand, they have some significant differences. CSR can be classified into internal and external CSR, of which the former focuses on employee health and safety, work-life balance, diversity, equal opportunity, and so on, whereas the latter includes firms' community, philanthropy, and environmental programs and activities concerning the external reputation of the organization [25]. GSCM integrates environmental thinking into supply chain processes [26] such as waste management, cleaner production and technologies, whereas RSCM encapsulates socially and/or environmentally responsible supply chain issues [27]. In addition, both SP and GP embody concern for social, environmental, and economic aspects within procurement processes [28], excluding product design, material sourcing and selection, manufacturing processes, and so on. Based on previous studies [29-32], SSCM can be defined as a process of planning, organizing, leading, and controlling to coordinate material, information, and capital flows along the supply chain through continuous innovation and decision-making, in order to realize an organization's social, environmental, and economic goals, which are derived from stakeholder requirements over the short and long term. Comparing with the above relevant concepts, SSCM includes the triple bottom line pillars of sustainability (economic, environmental, and social). Therefore, in this study, we focus specifically on SSCM.

The development of SSCM research is a dynamic and accumulating process related to research paradigms and scientific research projects in this field and will also be affected by the development of relevant technologies and research fields, such as the development of big data technology, algorithm optimization, etc. The literature review can outline the existing framework, theoretical research, and empirical contributions, and clarify the emerging trends of SSCM research. Several literature reviews have been conducted, many of which focus on a particular issue or aspect, such as blockchain technology for SSCM [33], stakeholder pressure in SSCM [4], SSCM in global supply chains [34] or the automotive industry [35]. Due to the increasing number of research papers on SSCM and increasingly diversified disciplines involved, these literature reviews, which are based on personal subjective judgment [36] and depend on the research level of scholars, cannot objectively and comprehensively reflect the knowledge structure, evolution, and trend of SSCM. However, there are limited bibliometric literature reviews on SSCM $[37,38]$ to help us gain a better understanding and overview of the evolution of this field. This paper seeks to fill in this gap to reveal social structure, conceptual structure, and intellectual structure, identify main concepts and research hotspots, and illuminate major specialties and emerging trends. As such, we explore the following main research questions:

RQ1: What is the social structure of the SSCM field?

RQ2: What is the conceptual structure of the SSCM field?

RQ3: What is the intellectual structure of the SSCM field?

We visualize and conduct a systematic scientometric review on 9151 publications spanning from 2007 to 2021. CiteSpace software is used in this paper to conduct co-author analysis, co-word analysis, and co-citation analysis [39]. The above analysis methods are all derived from the co-occurrence analysis technique, which is based on the basic assumption that when two authors, keywords, cited references, or other items appear in the same record, they can be considered to be related to some extent [36]. Comparing with prior studies, the novelties of the study are as follows. First, we reveal social structure, 
conceptual structure, and intellectual structure for the first time by using the bibliometric method, which can help readers understand the SSCM field from different dimensions. Second, we first collect a bibliographic dataset of SSCM area through both a query-based search approach and a citation expansion search method, which is considered more representative and comprehensive. Compared with traditional literature review, there are some specific advantages using CiteSpace software to conduct this systematic bibliometric review, which can help us obtain more objective research topics, track the development trend and evolution of knowledge structure, and can be complementary to a traditional literature review $[40,41]$. CiteSpace software can help scholars quickly focus on key information and identify the knowledge structure and evolution of a certain knowledge field. We expect this paper will show a big picture for researchers as well as practitioners.

The contributions of this paper are as follows. First, based on the analysis of coauthorship network and their institutions' network, we reveal relationships of collaboration and identify scholars and institutions that are most productive or located in structural holes. Second, based on the analysis of co-occurring keywords network, we identify the main concepts and research hotspots of the SSCM field. Third, based on the analysis of author, journal, and document co-citation network, we identify leading researchers, influential journals, emerging trends, and major milestones in the development and evolution of the SSCM field.

The rest of this paper is arranged as follows: Section 2 provides retrieval strategy and process about our data, and explains the methods we used. Section 3 reports results of social structure, conceptual structure, and intellectual structure of the SSCM field. Finally, the paper ends with conclusion and discussion, including main findings and contributions, limitations, and future researches.

\section{Materials and Methods}

\subsection{Material Collection}

\subsubsection{Retrieval Strategy}

The literature review of SSCM using CiteSpace software takes a bibliographic dataset, whose quality measured by recall and precision from the perspective of information retrieval as the basis of subsequent analysis. Therefore, formulating an optimal retrieval strategy in advance is of prime importance and significantly challenging, especially when we attempt to develop an overview and identify emerging trends of SSCM. Overall, there are two retrieval methods, namely a query-based search and a citation expansion search in electronic databases to attain documents for literature review [42].

The query-based search method typically requires terms or phrases to find records of publications relevant to a research topic of interest, which is perhaps the preferred way. For instance, the search query of Nimsai et al. [38] consisted of two phrases about SSCM: "sustainable development and supply chain" or "sustainability in supply chain" in the first search. Other valid search terms may include "sustainable supply chain" "supply chain and sustainab*", or "green supply chain management" to search for bibliographic records in the field of SSCM $[34,43,44]$. However, the detection of latent semantic relations or closely related concepts is the main drawback of the query-based search method, by which recall takes precedence over precision [42]. Some relevant papers may not appear by search term sieve, which poses profound challenges to the quality of the dataset. Based on the view of citation index that papers citing the source material deserve further consideration, the citation expansion search method can uncover potentially valuable and relevant papers that may be overlooked by the method of query-based search. For example, Li et al. [45] conducted a bibliometric analysis on hospitality management research, in which citation expansion was carried out on the core dataset using citation expansion function of the Web of Science database. Chen et al. [40] applied the method of topic term search and citation expansion, in order to cast a wider net in the bibliometric analysis of orphan drugs and rare diseases. 
Based on the above analysis, the query-based search combined with the citation expansion search method is applied to construct a representative and comprehensive dataset concerning SSCM research field in our retrieval process, which can maximize recall and precision. Specifically speaking, we firstly retrieve scholarly publications of SSCM as an initial dataset, namely the core dataset by the query-based search approach. Subsequently, the citation expansion search method is applied to expand the core dataset through citation links.

\subsubsection{Retrieval Process}

In order to source documents of SSCM for this review, we followed the retrieval process step by step: Web of Science (WoS) core collection, core dataset, expanded dataset, duplicates removal, and finally, total records. Figure 1 shows an explicit sequence of the retrieval process and corresponding results, which can mitigate subjectivity in selecting papers and ensure procedural transparency [46].

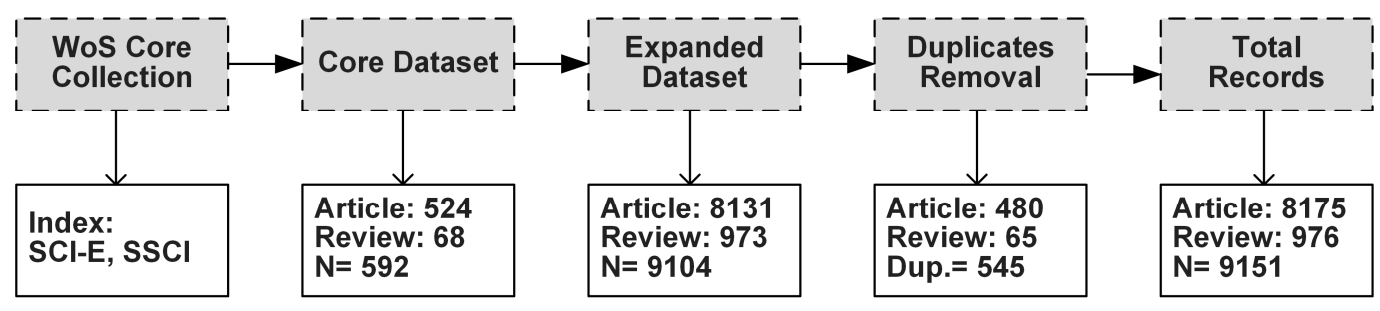

Figure 1. Retrieval process diagram.

First of all, the WoS Core Collection was selected for the reason that the database covers the world's leading peer-reviewed journals about SSCM research domains. In light of the interdisciplinarity of SSCM, such as environmental sciences, operations research, and business, we delimited the Science Citation Index Expanded (SCI-E) and Social Sciences Citation Index (SSCI) in the WoS Core Collection. Secondly, we referred to the study of Patel and Desai (2019) [47] who used "sustainable supply chain management" to retrieve peer-reviewed research articles. The search term "sustainable supply chain management" is also a professional term. An advanced search was conducted to construct the core dataset on 8 March 2021, using the topic search (TS)TS = "Sustainable Supply Chain Management" and restricting results by the English language and article/review document types with an open-ended timespan. Any papers published before the retrieval time deserve further investigation. It does not matter whether our dataset includes the whole year or not. According to the study of Bouazzaoui et al. [46], we delimited peer-reviewed articles and reviews, and excluded books, proceeding papers, and other unpublished works in order to control for the quality of publications. A total of 592 records, including 524 articles and 68 reviews, resulted from the query-based search approach. Then, we expanded the initial dataset through citation links by using the "Create Citation Report" function of the WoS database to construct the expanded dataset. This citation expansion search uncovered 8131 articles and 973 reviews that cite one or more publications of the core dataset. In addition, there are 545 duplicates including 480 articles and 65 reviews needing discarding when these two datasets were merged into one dataset. Eventually, as indicated in Figure 1, after refinement of excluding these duplicates, total unique records of 9151 peer-reviewed papers composed of 8175 articles and 976 reviews with 320,376 valid references were obtained. These papers published from 2007-2021 are considered for later scientometric review.

Figure 2 shows the distribution of publications of the SSCM domain over the years, which can be an indicator reflecting the macro development trend [48] and scholars' interests. As is showed in Figure 2, there was a rapid increasing trend from 2007 to 2020, especially after 2015, which indicates that SSCM research is getting more and more academic attention. The reason why publications in 2021 are only 430 is that our dataset only covers the first three month of the year. In 2007, there were only two papers, one of 
which [49] studied aspects of SSCM and introduced the concepts of first-, second-, and $\mathrm{n}$-order supply chains. The other paper [50] studied the pinch analysis approach combined with multi-criteria analysis to realize a more sustainable production. In 2017, a decade later, the quantity increased to 909 , to be $9.93 \%$ of total records. The number of publications hit the peak in 2020 when 2571 papers were published. Besides this, $79.29 \%$ of the publications (7256 out of 9151) were published in the last five years (2017-2021), suggesting that the SSCM research has entered a booming period.

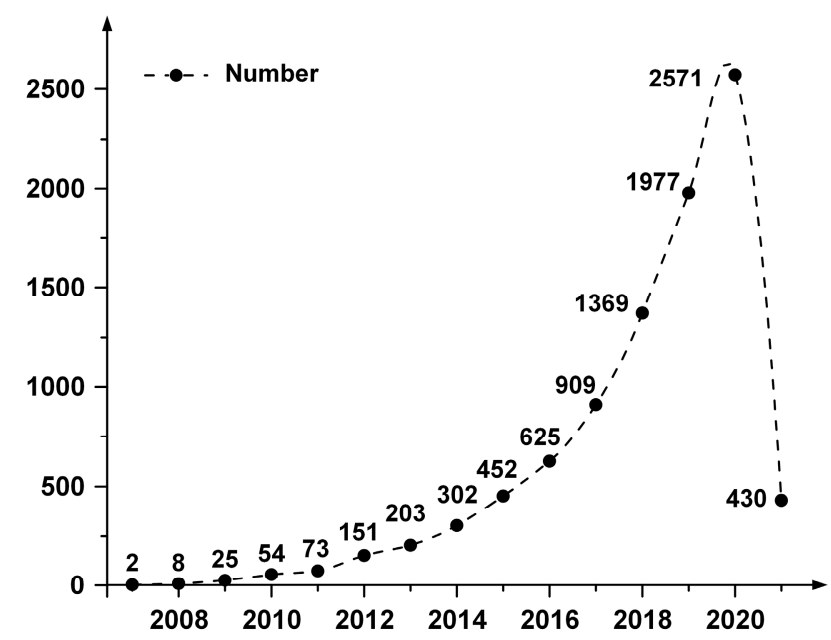

Figure 2. Distribution of sustainable supply chain management (SSCM) publications.

\subsection{Methods}

Currently, there are a variety of tools that can perform bibliometric analysis, such as CiteSpace, VosViewer, Bibexcel, etc. Each tool has different features and the choice depends on the requirements and intended purpose of the analysis. Compared with other tools, CiteSpace can be used to generate knowledge maps, show the knowledge structure and its dynamic changes, evaluate research status, reveal research hotspots, and predict research trends by analyzing literature in a certain research field. It is widely used in COVID-19 research [51], regenerative medicine [52], hotel management [45], innovation system [36], and other disciplines. Therefore, this paper conducts a bibliometric review on the SSCM field using CiteSpace 5.7 R2.

According to the study of [53], research techniques of co-author analysis, co-word analysis, and co-citation analysis are applied in this study to analyze different aspects of the SSCM field including social structure, conceptual structure, and intellectual structure. Firstly, using the method of co-author analysis, we map networks of co-authorship and co-authors' institutions in the SSCM field, so as to reveal the social structure. Secondly, using the method of co-word analysis, we map the network of co-occurring keywords to reveal the conceptual structure and identify main concepts and research hotspots. Thirdly, we carry on co-citation analysis, taking authors, journals, and documents as analysis units to reveal the intellectual structure of the SSCM field. Specifically, document co-citation analysis is based on the assumption that when two documents are cited by the third one at the same time, there is some correlation between the two documents. We also carry out clustering about references. The cited references in the cluster are cited by the academic group, which play the function of knowledge base, whereas the citing articles may be derived from the corresponding clustering and are considered as the research fronts [39]. Clustering quality can be measured by network modularity and weighted mean silhouette [51]. The former indicator reflects the clustering effect of the whole network structure. The larger the value is, the easier it is to divide the whole network into several groups with close connections among members but loose connections between groups. Modularity between $0.4-0.8$ is acceptable. The latter indicator measures the similarity 
among members, and the larger the value, the more significant a certain cluster division is [42].

This paper mainly uses metrics of frequency or count, betweenness centrality and citations burst to identify important nodes, which may be authors, journals, keywords, and documents [39]. The sizes of nodes with higher frequencies or counts are bigger than those with lower frequencies. For example, cited references with high citation frequency have been widely recognized by the scientific communities and have large citation rings in the figure [51]. The betweenness centrality, as a structural indicator, indicates the position of a particular node in the network. Nodes with high betweenness centrality (greater than or equal to 0.1 ) are located in structural holes and covered by purple circles in the figure, which have the potential to link various research themes and may bring transformative findings. Knowledge "turning points" can be identified by this metric [36]. From the perspective of information flow, scholars in the structure hole are supposed to connect different researchers and get in touch with various ideas, perspectives and viewpoints, which can make them more open-minded and creative. The citations burst, as a temporal metric, can be applied to identify particular nodes such as keywords or cited references, which have attracted wide attention of scholars in a certain period [40].

\section{Results}

In this study, we reveal social structure (RQ1), conceptual structure (RQ2), and intellectual structure (RQ3) of the SSCM field by the methods of co-author analysis, co-word analysis, and co-citation analysis.

\subsection{Social Structure of SSCM Field}

We focus on network of co-authors and their institutions in this section to analyze social structure.

\subsubsection{Co-Authorship Network}

In order to study key authors and their collaborative relationships in the field of SSCM, this paper analyzes the authors of 9151 literatures related to SSCM. The co-authorship network was generated by CiteSpace whose parameters are set up as follows: top 50 Per year (2007-2021), $\mathrm{LRF}=3, \mathrm{LBY}=5$, and $\mathrm{e}=2$. To make the map easier to visualize, we pruned the sliced networks and merged networks based on a pathfinder algorithm, resulting in a network with 607 nodes and 585 links whose largest subnetwork is shown in Figure 3. Each node is labeled by the corresponding author. The linkage between two nodes indicates that two authors collaborated to research in the same paper. The thicker the linkage is, the high the level of cooperative relationship is. In addition, the nodes with frequency greater than or equal to 15 are displayed. From Figure 3, we can identify cooperative relationships among scholars and productive scholars clearly in the largest subnetwork.

In terms of cooperative relationships, the density of the network is 0.0037 , indicating that authors' group has not yet formed strong relationships of collaboration. There are only two scholars for which the betweenness centrality is more than 0.1, including Joseph Sarkis (with the betweenness centrality of 0.17 ) and Kannan Govindan (0.11). These two authors are located at structural holes. It is clear that Joseph Sarkis (with the count of 103), Kannan Govindan (99), and Minglang Tseng (72) are the top three most productive scholars, followed by Angappa Gunasekaran (59), Charbel Jose Chiappetta Jabbour (53), Stefan Seuring (50), Sunil Luthra (46), Biswajit Sarkar (42), Ana Beatriz Lopes De Sousa Jabbour (41), and Sachin Kumar Mangla (41) in the field of SSCM research. From the perspective of citation burst, there are 63 burst authors, of which 20 authors have a duration no less than four years. In addition, the following authors have been bursting to present: Minglang Tseng, Syed Mithun Ali, Ming K Lim, Rakesh D Raut, Morteza Rastibarzoki, Sachin Kumar Mangla, and Wenyan Song who have burst durations no less than four years. 


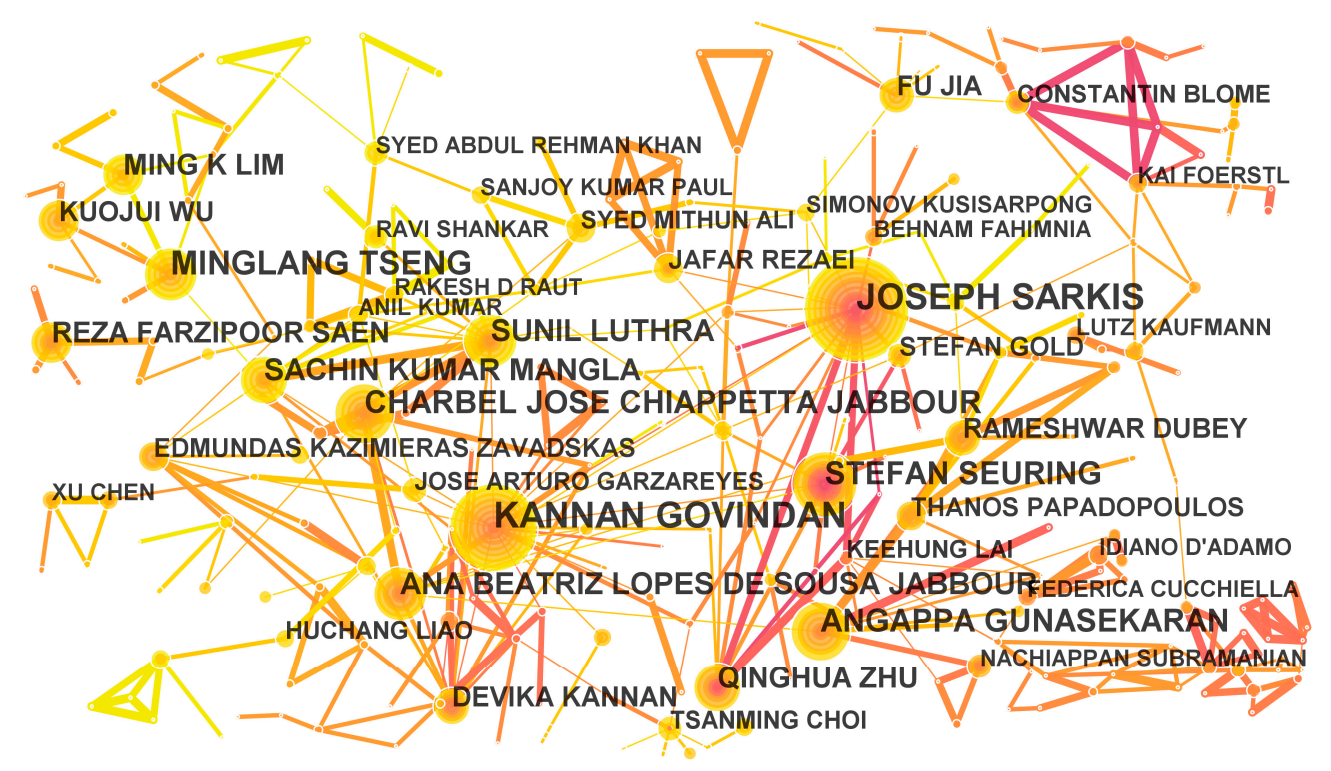

Figure 3. Co-authorship network.

\subsubsection{Co-Authors' Institutions Network}

In order to explore core institutions and relationships of cooperation in the field of SSCM, we generated a network of co-authors' institutions. CiteSpace parameters are similar to the co-authorship network. The font size of an organization is proportional to the number of publications. The connection and thickness between nodes represent the cooperation relationship and frequency between two institutions.

The nodes and linkages number of the whole cooperation network of research institutions are 291 and 283, respectively. The network density is 0.0067 . The largest subnetwork has 226 node network members, accounting for $77 \%$ of the total network nodes, shown in Figure 4. From Figure 4, we can identify the institutions that contribute most papers and/or have occupied crucial positions in the largest subnetwork. In terms of publications frequencies of various institutions, Hong Kong Polytech University (with 170 publications), Islamic Azad University (155), University of Southern Denmark (138), Dalian University of Technology (104), and University of Tehran (99) are the top five most productive institutions, followed by Polytechnic University of Milan (94), University of Kassel (88), University of Nottingham (81), Worcester Polytechnic Institute (79), and Iran University of Science and Technology (71). It is a remarkable fact that other institutions in China have played an active role in the research progress on SSCM, such as University of Electronic Science and Technology of China (68), Tianjin University (67), Chongqing University (64), Sichuan University (63), Tongji University (61), Tsinghua University (55), and so on. In terms of betweenness centrality, institutions such as University of Sheffield (0.55), University of Kent (0.34), University of Liverpool (0.32), University of Plymouth (0.31), University of Massachusetts Dartmouth (0.31), Aalto University (0.31), and Chalmers University of Technology (0.31) have occupied crucial positions in the research network of SSCM research. In addition, the citation burst of institutions can be an indicator reflecting institutions that publish many papers during a short period. There are 90 institutions with citation burst, of which eight institutions have been lasting for more than five years, including University of Bath (with a burst strength of 7.22, from 2009 to 2016), Arizona State University (7.44, 2011-2017), Oregon State University (5.23, 2010-2016), Griffith University (3.26, 20112017), University of Padua (9.19, 2012-2017), University of Strathclyde (6.42, 2012-2017), Linkoping University (5.49, 2012-2017), and University of Twente (2.87, 2011-2016). 


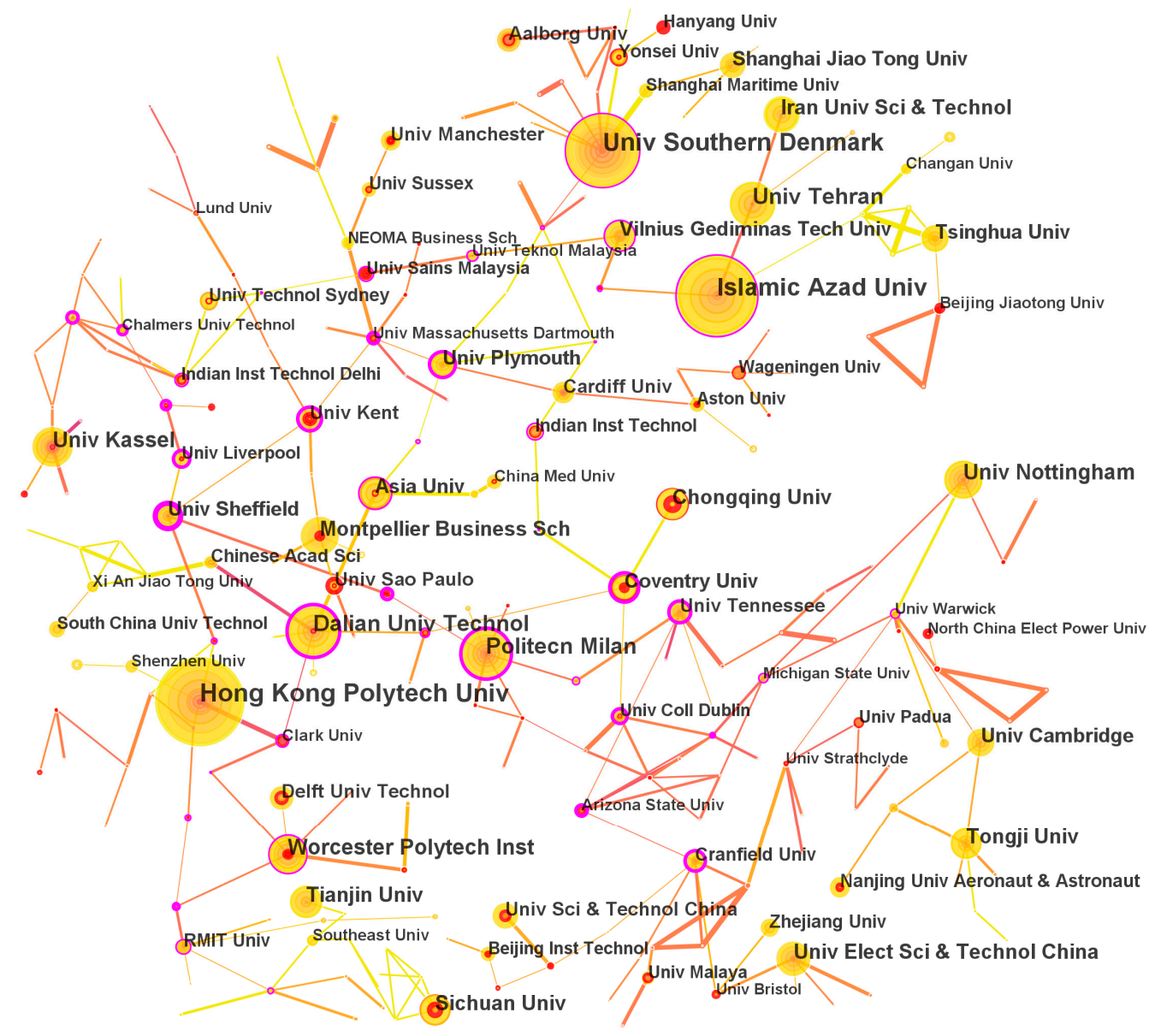

Figure 4. Co-authors' institutions network.

\subsection{Conceptual Structure of SSCM Field}

In this section, we apply the method of co-word analysis to reveal the conceptual structure, and identify main concepts and research hotspots.

\subsubsection{Co-Occurring Keywords Network}

Keywords, as representative words of a paper, are high-level summary of content [48], which can enable researchers to gain an understanding of the core and essence of the study. High frequency and betweenness centrality of co-occurrence of keywords can reflect main concepts in its research fields. Therefore, the method of co-word analysis is applied to reveal the conceptual structure of SSCM fields. For the purpose of conducting a co-word analysis utilizing CiteSpace software, the configuration parameters were set up as follows: top 30 Per year (2007-2021), $\mathrm{LRF}=3, \mathrm{LBY}=5$, and $\mathrm{e}=2$. The sliced networks and merged network map of co-occurrence were pruned by a pathfinder algorithm. The network of co-occurring keywords, with 129 nodes and 156 links, is shown in Figure 5. As is shown in Figure 5, each keyword is represented by a circle-node whose size is a sign of the frequency of a keyword. The color of linkages between keywords indicates the first time when two keywords occurred in the same paper. The brighter the color of linkage is, the closer the first year of co-occurrence is to the present. In addition, the nodes with frequency greater than or equal to four are displayed. We can also obtain the count and centrality of keywords from CiteSpace. The importance of keywords cannot only be judged by the frequency or count, but also its betweenness centrality in the network. Table 1 lists the top 20 keywords with high count or centrality. From Figure 5, we can identify keywords with high frequency and/or with high betweenness centrality and draw out main concepts. 


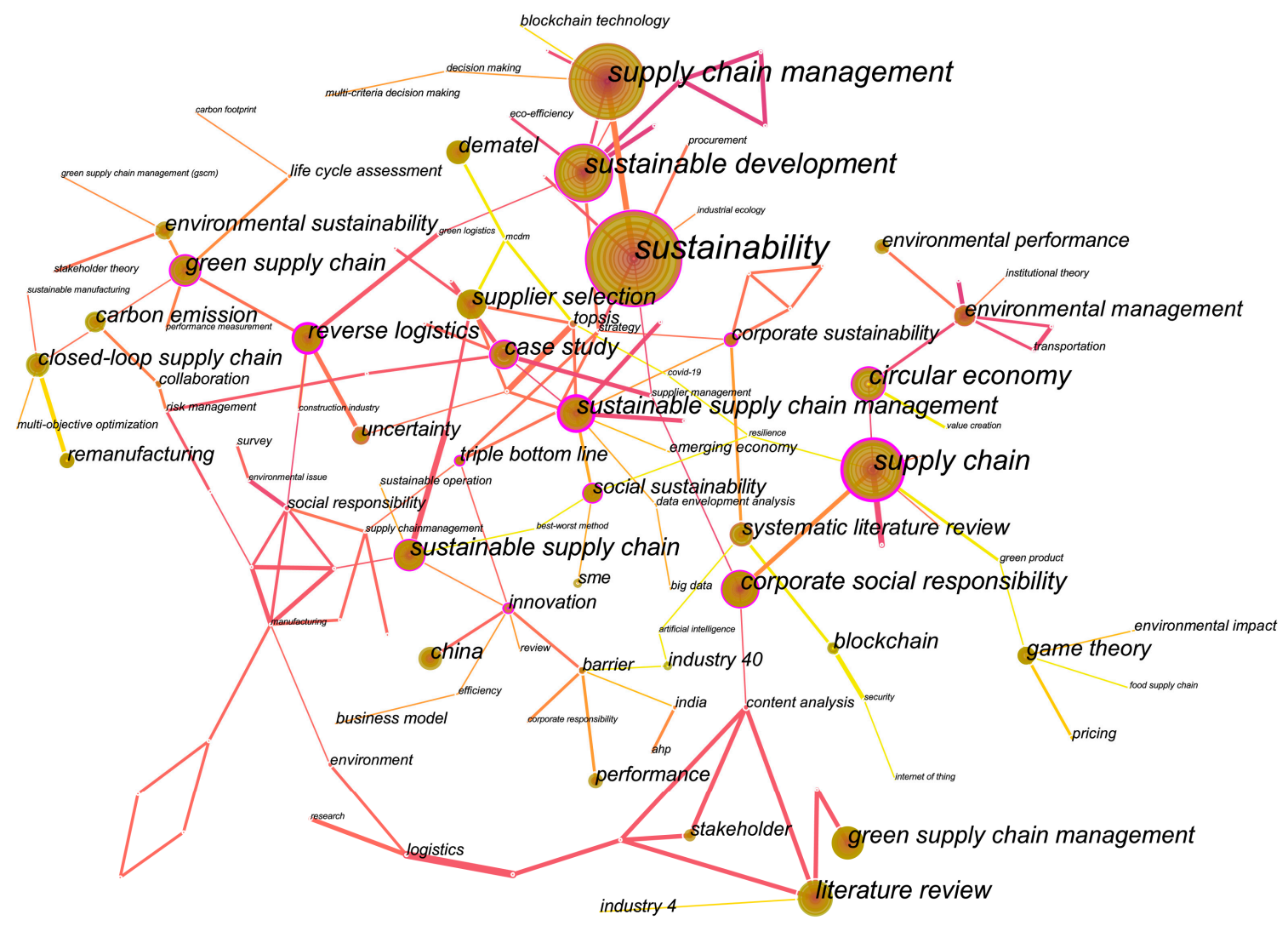

Figure 5. Co-occurring keywords network.

Table 1. Top 20 keywords with high count or betweenness centrality.

\begin{tabular}{|c|c|c|c|c|}
\hline No. & Count & Keywords & Centrality & Keywords \\
\hline 1 & 1359 & sustainability & 0.47 & supply chain \\
\hline 2 & 573 & supply chain management & 0.42 & sustainable supply chain management \\
\hline 3 & 446 & supply chain & 0.42 & reverse logistics \\
\hline 4 & 345 & sustainable development & 0.38 & strategy \\
\hline 5 & 322 & circular economy & 0.32 & corporate social responsibility \\
\hline 6 & 203 & corporate social responsibility & 0.31 & sustainability \\
\hline 7 & 203 & sustainable supply chain & 0.31 & corporate sustainability \\
\hline 8 & 196 & literature review & 0.31 & supplier management \\
\hline 9 & 184 & sustainable supply chain management & 0.29 & sustainable development \\
\hline 10 & 170 & green supply chain management & 0.29 & sustainable supply chain \\
\hline 11 & 158 & green supply chain & 0.29 & green supply chain \\
\hline 12 & 155 & supplier selection & 0.29 & social sustainability \\
\hline 13 & 143 & case study & 0.29 & innovation \\
\hline 14 & 132 & reverse logistics & 0.29 & resilience \\
\hline 15 & 114 & china & 0.28 & social responsibility \\
\hline 16 & 109 & blockchain & 0.24 & manufacturing \\
\hline 17 & 107 & environmental management & 0.23 & triple bottom line \\
\hline 18 & 107 & closed-loop supply chain & 0.2 & circular economy \\
\hline 19 & 106 & systematic literature review & 0.2 & case study \\
\hline 20 & 103 & dematel & 0.18 & fuzzy set theory \\
\hline
\end{tabular}

In terms of frequency, sustainability with the frequency of 1359 ranks first of all the keywords. Supply chain management is the second high count keyword, followed by supply chain (446). Scholars also pay great attention to circular economy (322) and corporate social responsibility (203). The keywords sustainable supply chain management (184), green supply chain management (170), and green supply chain (158) represent the 
subdivided classification of supply chain management studied by scholars. The keyword literature review (196) and case study (143) represent the methods of SSCM research. Supplier selection (155) and reverse logistics (132) are also high frequency keywords.

On the other hand, keywords with high betweenness centrality indicate that they are in the center of network and important in linking other keywords or other research topics. The centrality of nodes in a purple circle are greater than 0.1. For example, the centrality of supply chain is 0.47 , greater than 0.1 , which links corporate social responsibility, circular economy, resilience, green product, and so on. Table 1 shows the top 10 high betweenness centrality value of keywords, in which the keywords supply chain, sustainable supply chain management, and reverse logistics show the highest betweenness centrality among all others at $0.47,0.42$ and 0.42 , respectively. Other keywords such as strategy, corporate social responsibility, sustainability, corporate sustainability, and supplier management at betweenness centrality values range from 0.3 to 0.4 . Keywords whose centrality is greater than 0.1 deserve to be studied further.

Considering both criteria of frequency and betweenness centrality, the values of following keywords are high: sustainability, supply chain, sustainable development, circular economy, corporate social responsibility, sustainable supply chain, sustainable supply chain management, green supply chain, case study, and reverse logistics. These keywords can be summarized into five main concepts: sustainable supply chain management, green supply chain management, circular economy, corporate social responsibility, and reverse logistics.

\subsubsection{Keywords Burst Analysis}

The notable increase in the frequency of a keyword during a relatively short period of time usually reflects research hotspots, which are paid special attention by the scientific community. We carried out keywords burst detection to identify research hotspots of the SSCM domain using CiteSpace [54]. Table 2 shows 25 keywords with bursts of at least two years. In chronological order, the burst keywords in the SSCM field have been changing over the years from 2007 to 2021.

Table 2. 25 keywords with burst of at least two years.

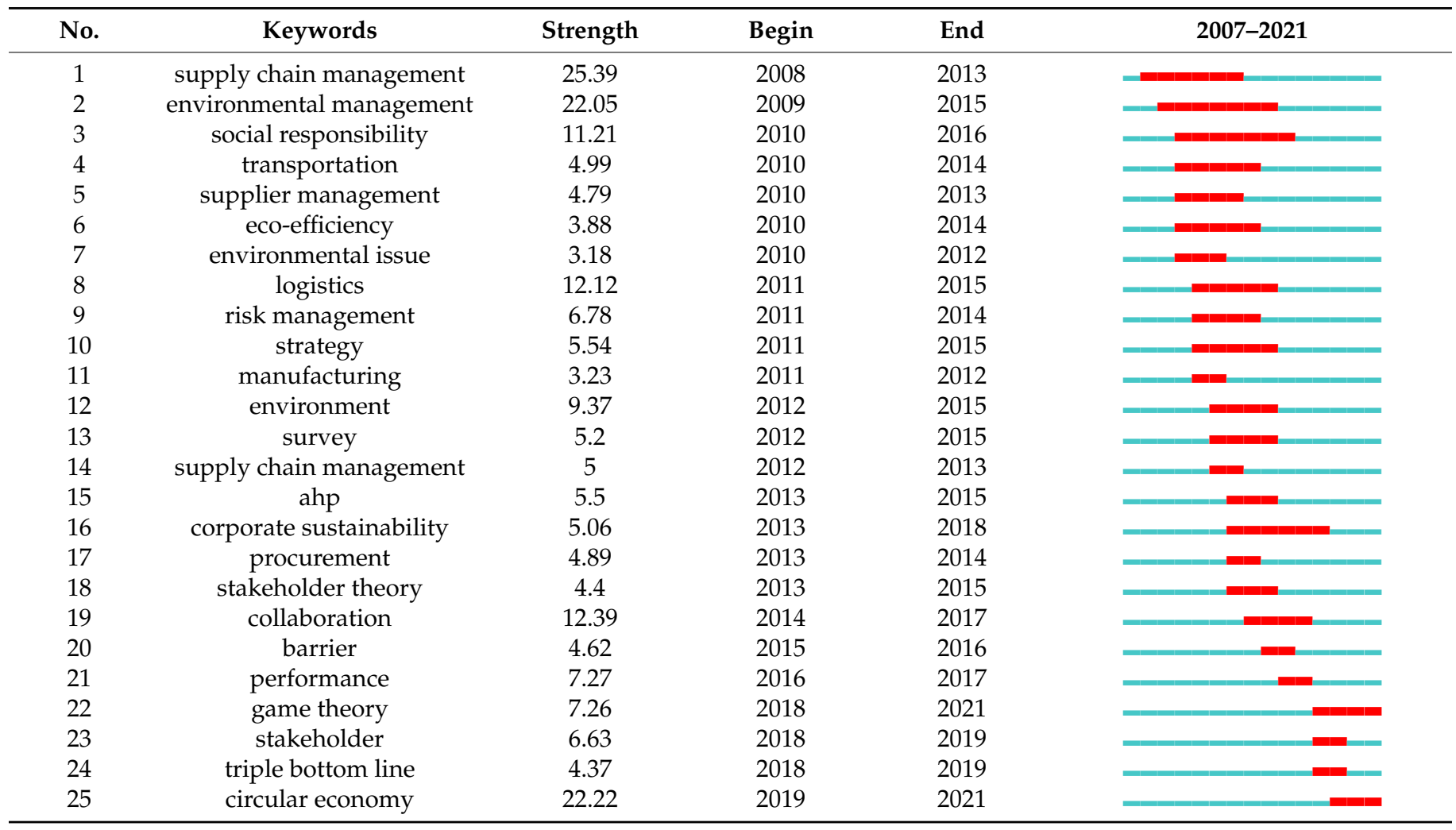


The keywords with a burst period greater than five years include supply chain management (2008-2013), environmental management (2009-2015), social responsibility (20102016), transportation (2010-2014), eco-efficiency (2010-2014), logistics (2011-2015), strategy (2011-2015), and corporate sustainability (2013-2018), which indicate that these topics got more attention and are more influential than other keywords, thus, they became research hotspots of the SSCM domain in corresponding periods. Besides, the game theory and circular economy beginning bursting in 2018 and 2019, respectively, continue bursting to the present, which are research hotspots currently.

From the point of view of burst strength, supply chain management (25.39) is the strongest burst, followed by circular economy (22.22), environmental management (22.05), social responsibility (11.21), transportation (4.99), and supplier management (4.79), which are research hotspots in their corresponding periods. It is noteworthy that circular economy is not only bursting to present, but also has high burst strength. This keyword appeared in 322 records including 50 records in 2018, 87 records in 2019, and 126 records in 2020 in our dataset. On the whole, we argue that the research hotspots of the SSCM field currently are game theory and circular economy related researches.

\subsection{Intellectual Structure of SSCM Field}

In this section, we apply the method of co-citation analysis to reveal intellectual structure by analyzing cited authors, journals, and documents.

\subsubsection{Author Co-Citation Network}

Author co-citation network is generated to identify highly cited scholars whose publications are widely recognized by research communities in SSCM research. When two scholars are cited in the same publications, the relationship of author co-citation occurs. We take 9151 peer-reviewed papers' references as analysis objects. The highly cited authors may not be SSCM scholars, but their contributions certainly have a great impact on the development of the SSCM field. CiteSpace configurations were set up as follows: Top N $(\mathrm{N}=50)$ Per year $(2007-2021), \mathrm{LRF}=3, \mathrm{LBY}=5$, and $\mathrm{e}=2$. Sliced and merged networks were pruned according to the pathfinder algorithm, which resulted in 233 nodes and 419 links. The bigger the size of each node, the more citations the scholar has. The thicker linkage between two nodes is, the more times two authors are cited in the same papers. The nodes with citations over 200 are labeled by the corresponding first author. The nodes with betweenness centrality no less than 0.1 are covered by a purple circle. From Figure 6 , we can identify cited authors with high citations and/or with high betweenness centrality and draw out leading researchers.

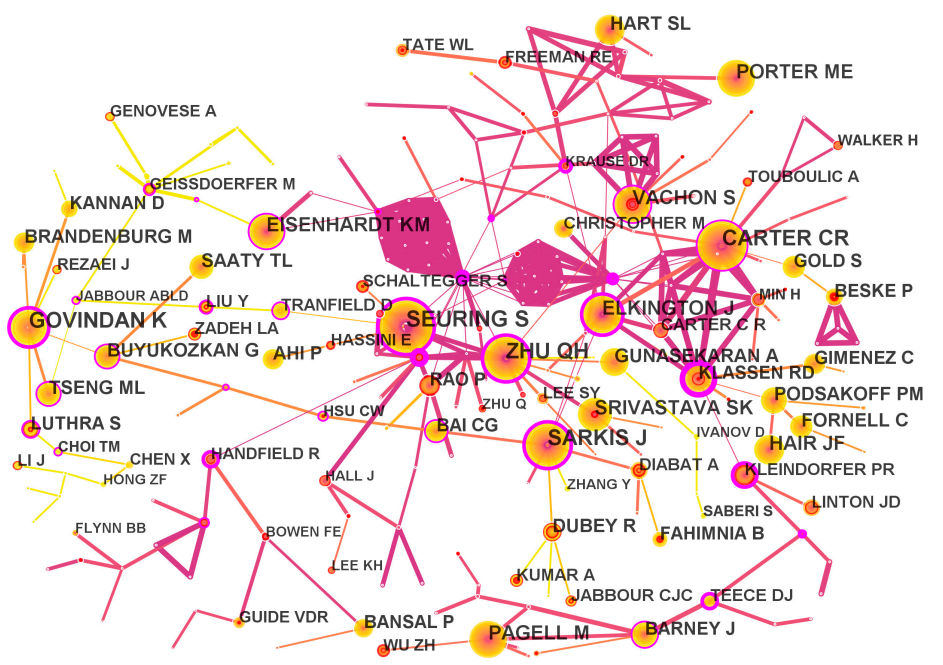

Figure 6. Author co-citation network. 
As is shown in Figure 6, the top five most highly cited authors are Stefan Seuring (with 2158 citations), Kannan Govindan (1514), Craig R. Carter (1478), Qinghua Zhu (1453), and Joseph Sarkis (1328). Figure 7 shows the citation distribution of top five most cited authors. From Figure 7, we can know that on the whole, citations of these five scholars show a rapidly increasing trend from 2008 to 2020. Professor Stefan Seuring of Universität Kassel in Germany is cited the most every year, except for 2020. It is worth mentioning that Kannan Govindan, who works at China Institute of FTZ Supply Chain in Shanghai Maritime University and Centre for Sustainable Supply Chain Engineering in University of Southern Denmark, was cited the first time in 2014, and in 2020 his citations exceeded Stefan Seuring and ranked first. Professor Kannan Govindan is the 2018 Highly Cited Researcher (Clarivate Analytics) and his research interests mainly include reverse logistics, closed-loop supply chain, SSCM, and GSCM. Professor Craig R. Carter works at Arizona State University, whose expertise areas include SSCM, supply chain management decisionmaking and negotiation. Professor Qinghua Zhu works at Antai College of Economics and Management, Shanghai Jiao Tong University, whose research interests include GSCM, corporate social responsibility, and remanufacturing management. Professor Joseph Sarkis works at the School of Business, Worcester Polytechnic Institute, whose research interests include supply chain management, multi-criteria decision-making, and so on.

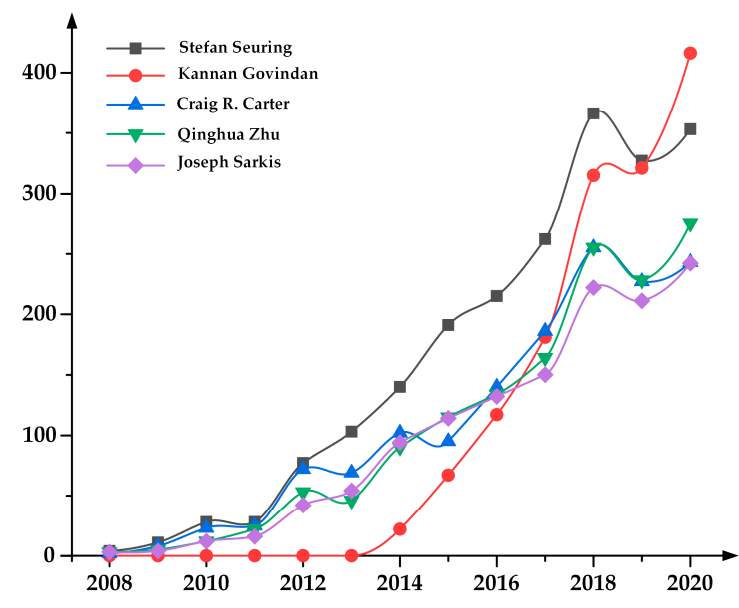

Figure 7. Citation distribution of the top five most cited authors.

It is noteworthy that professor Kathleen M. Eisenhardt is not a SSCM scholar, but she is in Figure 6. Many of her papers are cited by SSCM scholars and her contributions can be considered as the knowledge base (theory or method) for the SSCM field. For example, Sarkis et al. (2011) [55] referred to Eisenhardt's paper titled "Agency theory: an assessment and review". Govindan et al. (2014) [56] referred to Eisenhardt's paper titled "Better stories and better constructs: the case for rigor and comparative logic". Her paper titled "Theory Building From Cases: Opportunities And Challenges" [57] is highly cited by SSCM scholars.

In terms of betweenness centrality, there are 16 scholars whose betweenness centrality are no lower than 0.2 , indicating they are more influential than other scholars and exert a great impact the development of SSCM research. The top 10 of these authors include Thomas Dyllick (with a centrality of 0.64), Charles J. Corbett (0.5), Lutz Preuss (0.47), Robert D. Klassen (0.42), John Elkington (0.39), Qinghua Zhu (0.33), Joseph Sarkis (0.3), Paul R. Kleindorfer (0.27), and Kannan Govindan (0.26). When authors have both high citation and betweenness centrality, they can be considered as influential or leading scholars [36,58]. In this paper, taking citations count and betweenness centrality simultaneously, the following scholars, whose citation and centrality exceed 500 and 0.1 , can be regarded as leading researchers: Stefan Seuring, Kannan Govindan, Craig R. Carter, Qinghua Zhu, Joseph Sarkis, John Elkington, Stephan Vachon, Kathleen M. Eisenhardt, Ming-LangTseng, and Gülçin Büyüközkan. 
In addition, we can also identify influential scholars from the point of citation bursts, that is, a scholar is cited much during a short period. The citations of several authors have been bursting to present, including Sunil Luthra (with a burst strength of 50.88, from 2018), David J. Teece $(36.45,2018)$, Behnam Fahimnia $(24.1,2018)$, Yan Liu $(80.21,2019)$, Andrea Genovese $(61.07,2019)$, Martin Geissdoerfer $(59.93,2019)$, Xu Chen $(59.01,2019)$, Jing Li $(58.79,2019)$, Jafar Rezaei $(52.81,2019)$, Charbel José Chiappetta Jabbour (49.24, 2019), L.A. Zadeh (39.34, 2019), Amit Kumar (37.48, 2019), and Rameshwar Dubey (33.98). The publications of these authors are worth studying because of their significant impact on SSCM research.

\subsubsection{Journal Co-Citation Network}

In this section, we first analyze the source of publications and then detect the most representative cited journals in the SSCM field.

It is found that 9151 papers related to the SSCM field are published in 889 journals, the top 10 of which are listed in Table 3. These 10 journals published 4029 papers, which account for $44.03 \%$ of the total records, which contribute greatly to progress in this field and reflect a high concentration. As for frequency, the most productive journal is the Journal of Cleaner Production publishing 1434 SSCM related papers and accounting for $15.67 \%$ of papers of the total records, followed by Sustainability (10.96\%), International Journal of Production Economics (3.81\%), International Journal of Production Research (2.87\%), Business Strategy and the Environment (2.19\%), and Supply Chain Management-An International Journal $(1.90 \%)$. Because a higher impact factor does not equate to a higher journal quality, we build on ABS journal rankings (2018). There are five journals rated 3, including the International Journal of Production Economics, International Journal of Production Research, Business Strategy and the Environment, Supply Chain Management-An International Journal, and Production Planning $\mathcal{E}$ Control, which are highly regarded and very selective in what they publish. Journal of Cleaner Production, Computers \& Industrial Engineering, and International Journal of Physical Distribution \& Logistics Management are rated 2, which indicate papers in these journals are fully refereed according to accepted standards and conventions. Besides, these journals have a pluralistic nature, such as environmental sciences, engineering, operations research, business, management, and so on, which indicate that the academic field of SSCM is interdisciplinary [59].

Table 3. Top 10 journals of SSCM.

\begin{tabular}{ccccc}
\hline No. & Source & Frequency & \% & ABS 2018 \\
\hline 1 & Journal of Cleaner Production & 1434 & 15.67 & 2 \\
2 & Sustainability & 1003 & 10.96 & - \\
3 & International Journal of Production Economics & 349 & 3.81 & 3 \\
4 & International Journal of Production Research & 263 & 2.87 & 3 \\
5 & Business Strategy and the Environment & 200 & 2.19 & 3 \\
6 & Supply Chain Management-an International Journal & 174 & 1.90 & 3 \\
7 & Computers \& Industrial Engineering & 161 & 1.76 & 2 \\
8 & Production Planning \& Control & 158 & 1.73 & 3 \\
9 & Resources Conservation and Recycling & 153 & 1.67 & -1.46 \\
10 & International Journal of Physical Distribution \& Logistics Management & 134 & 2 & 1.46 \\
\hline
\end{tabular}

We then generated a journal co-citation map to detect and evaluate influential journals that contribute to the development of SSCM research and serve as the knowledge base to some degree, as shown in Figure 8. CiteSpace configurations were set up as follows: Top $N(N=50)$ per year $(2007-2021), L R F=3, L B Y=5$, and $e=2$. Sliced and merged networks were pruned by the pathfinder algorithm, which resulted in 129 nodes and 247 links. The node sizes of cited journals and linkage thickness indicate citations and co-citations, respectively. The nodes with count exceeding 500 are labeled by corresponding 
abbreviations of journals. From Figure 8, we can identify cited journals with high citations and/or with high betweenness centrality and draw out influential journals.

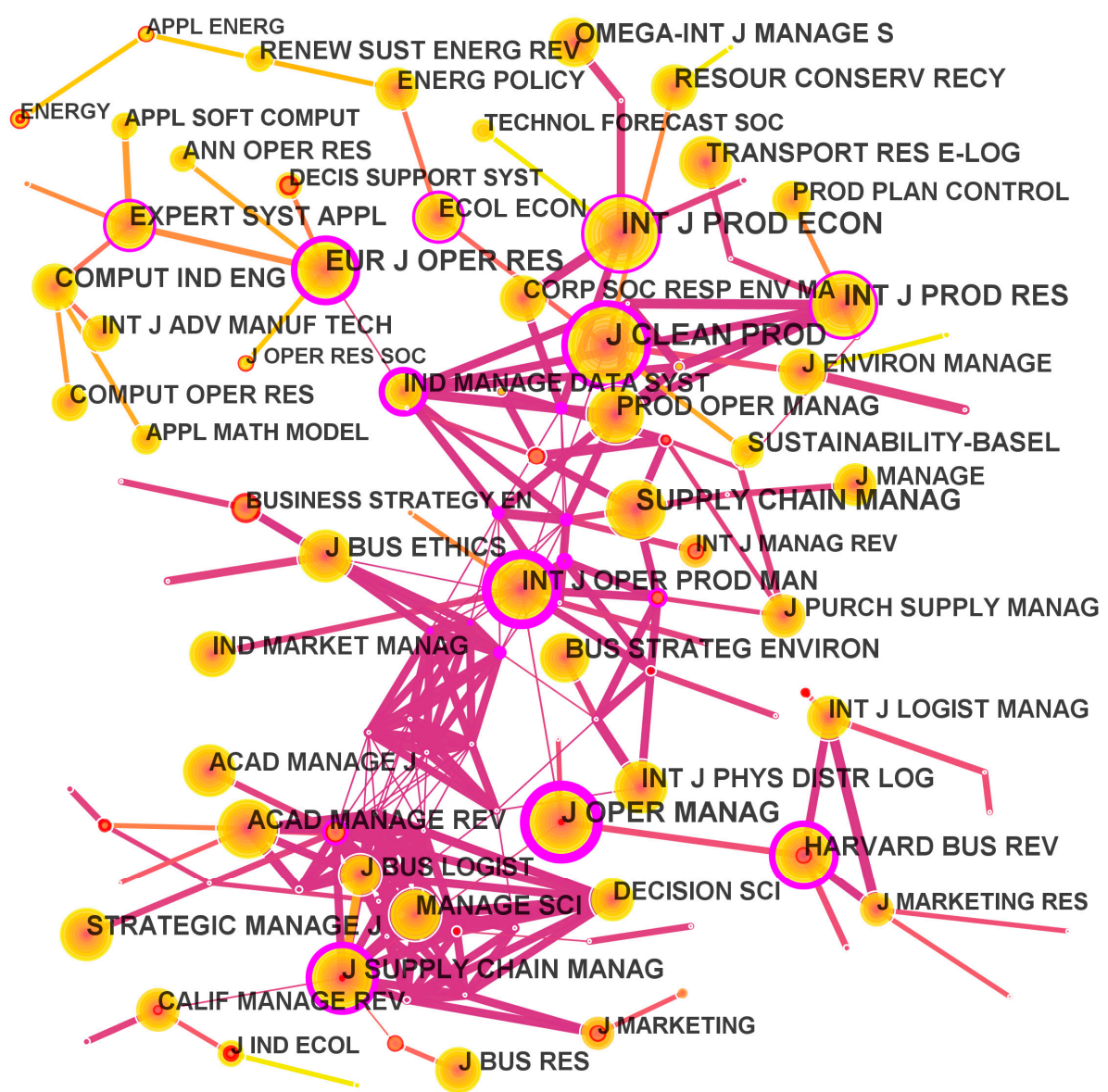

Figure 8. Journal co-citation network.

Based on co-citation frequencies (namely, node sizes) of local co-citation in our dataset, journals with the most citations include Journal of Cleaner Production (with 6936 citations), International Journal of Production Economics (5462), International Journal of Production Research (4020), European Journal of Operational Research (3790), Supply Chain Management-An International Journal (3194), Journal of Operations Management (3192), International Journal of Operations \& Production Management (2892), Omega-international Journal of Management Science (2616), Journal of Business Ethics (2597), International Journal of Physical Distribution $\mathcal{E}$ Logistics Management (2559), and Sustainability (2513). These journals are all cited more than 2500 times, which can be deemed as influential journals in SSCM research. It is noteworthy that the top 10 sources of publications and most cited journals overlap to some extent, such as Journal of Cleaner Production and International Journal of Production Economics.

In terms of betweenness centrality (nodes with purple circle) of cited journals, the following journals whose centrality exceed 0.3 include International Journal of Operations $\mathcal{E}$ Production Management (with a centrality of 0.56), Journal of Operations Management (0.43), Journal of Supply Chain Management (0.36), and Industrial Management \& Data Systems (0.36), which act as bridges linking other journals to a large extent. In addition, there are 42 cited journals with the strongest citation bursts, of which Applied Energy (with a burst strength of 107.97, 196 citations in 2020), Journal of the Operational Research Society $(102.98,273)$, and Energy $(87.32,297)$ have been bursting from 2019 to 2021 . These three journals are categorized as Q1 or Q2 from JCR 2019, of which papers are worth studying. 


\subsubsection{Document Co-Citation Network}

When a group of documents is frequently cited in conjunction with other documents, this cluster may represent a certain research theme. Compared with other clusters, each cluster member is cited more frequently by a group of the same citing articles. In this section, based on 320,376 valid references cited in the 9151 records in our dataset, we applied the method of document co-citation analysis to visualize the landscape view of the SSCM field and analyze underlying knowledge base and research fronts. CiteSpace parameter settings are set up as follows: g-index $(k=40)$ Per year $(2007-2021), \mathrm{LRF}=3$, $\mathrm{LBY}=5, \mathrm{e}=2$ and Pruning = None. The synthesized network of co-cited references in SSCM research, with 2327 nodes and 12,165 links, is shown in Figure 9. We then carried out clustering, which generated 220 clusters, which are labeled with title terms extracted from citing articles through the Log-likelihood ratio (LLR) algorithm. Compared with the latent semantic indexing (LSI) algorithm focusing on identifying common theme, the LLR algorithm tends to emphasize unique topics [39]. Figure 9 shows 19 clusters, including \#0 Chinese manufacturer, \#1 sustainable supply chain management, \#2 green supply chain management, \#3 sustainable supplier selection, \#4 circular economy, \#5 and-trade regulation, \#6 closed-loop supply chain, \#7 sustainable production network, \#8 blockchain technology, \#9 supply chain management profession, \#10 big data analytics, \#11 corporate sustainability strategies, \#12 COVID-19 pandemic, \#13 supply chain resilience, \#14 green human resource management, \#15 best-worst method, \#16 logistics issue, \#21 energy efficiency, and \#26 logistics performance, which are major specialties of the SSCM field. Each cluster signifies distinct aspects of SSCM issues and topics. For instance, the brilliant yellow-colored area at the lower right quadrant is labeled as \#8 blockchain technology, which indicates that cluster \#8 is cited by papers about blockchain technology related topics. The color of the convex hull of each cluster indicates mean year calculated on publication year of the cluster's members. In addition, the brighter the color is, the closer average year of one cluster is to the present. The quality of co-citation clusters is supposed to meet both criteria of modularity and weighted mean silhouette, which deserves to be thoroughly investigated. The modularity of the network is 0.7664 , which is considered as a higher value, denoting that a well-structured network is developed and the specialties in SSCM fields are clearly defined. The weighted mean silhouette, as an indicator measuring the internal homogeneity of each cluster, is 0.8659 , signifying the clustering is highly reliable and the members of corresponding cluster are more similar than other clusters' members.

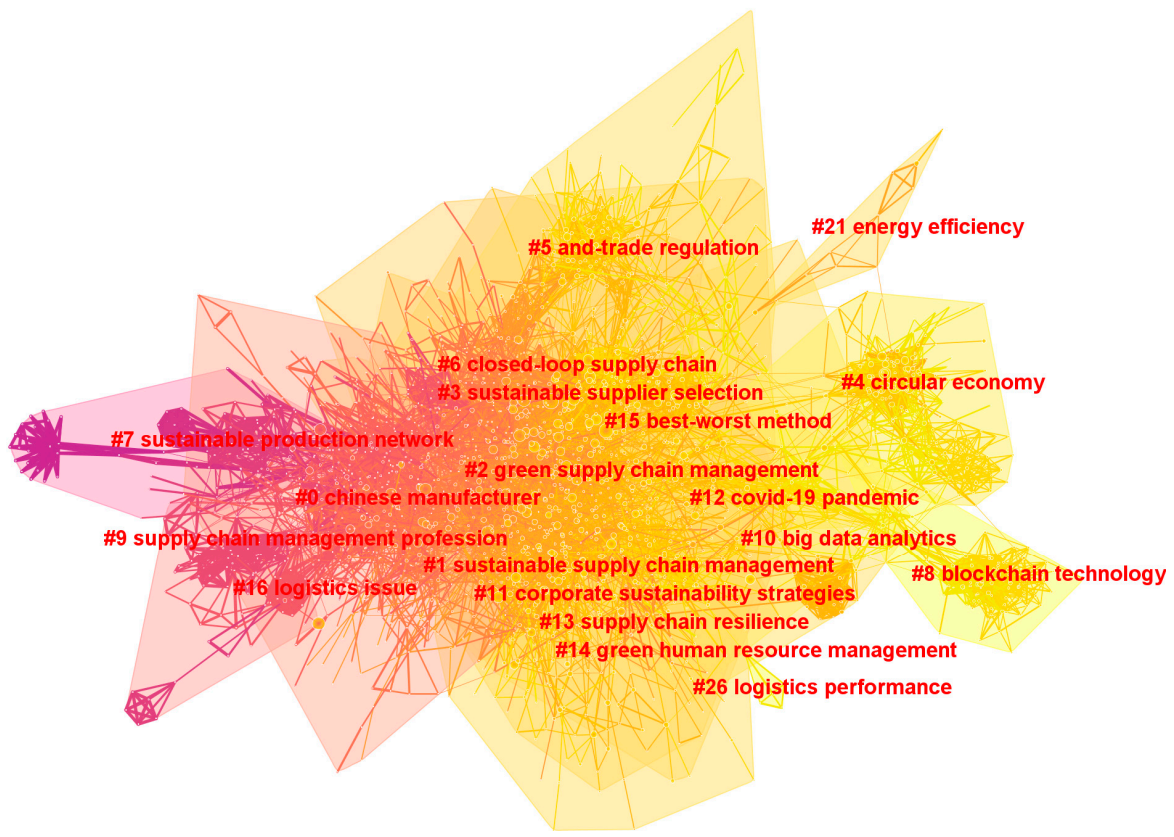

Figure 9. A landscape view of the co-citation network. 
A timeline view of clusters is generated to show the origin, evolution, and time span of each cluster in Figure 10. Disappearance of a cluster may not mean that scholars have lost interest in this field, but may mean that they continue to explore new research directions [39]. As is depicted in Figure 10, each cluster's members are showed in chronological order along the horizontal axis, whereas clusters are displayed vertically from top to down according to their sizes.

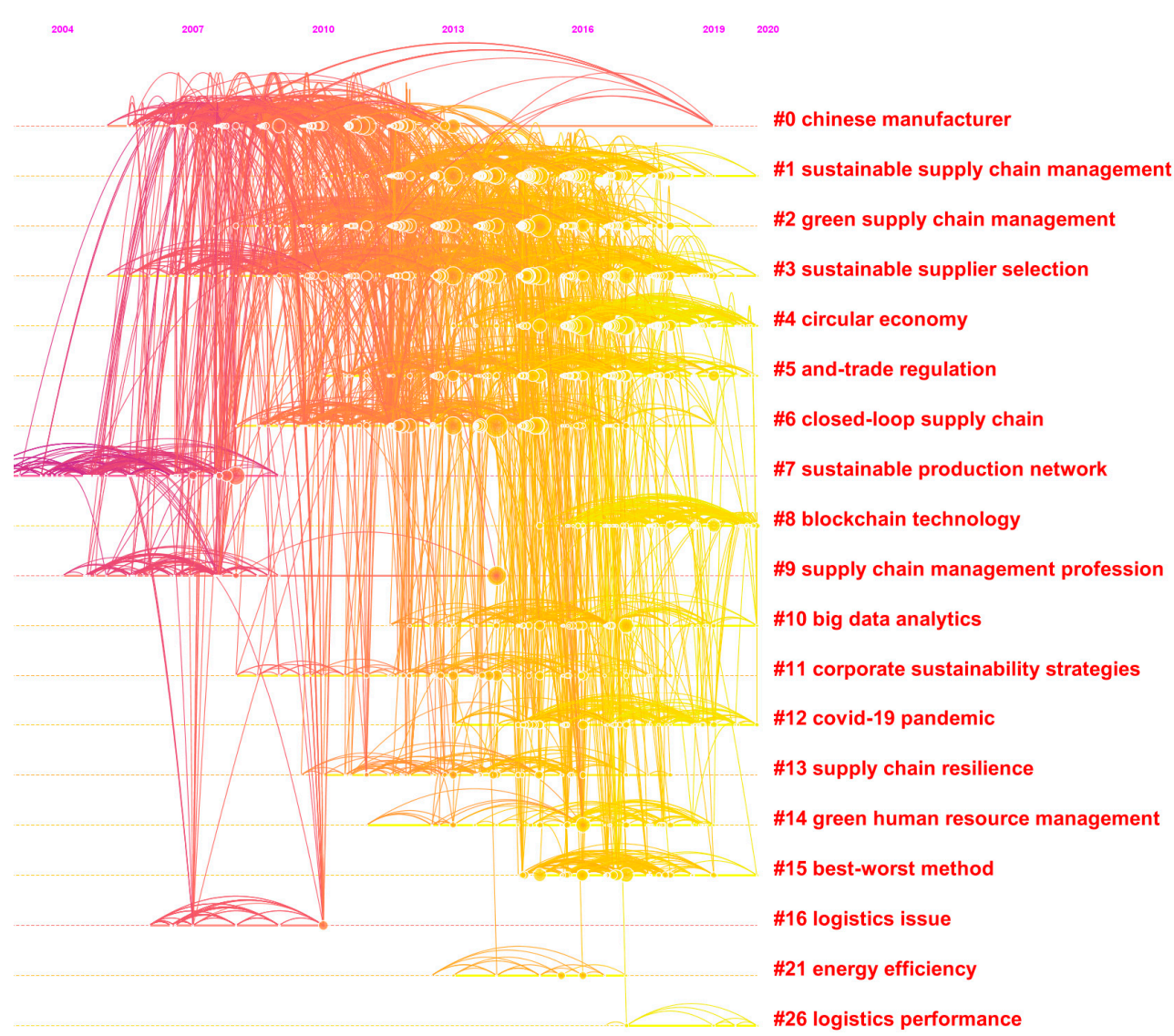

Figure 10. Co-citation timeline visualization of the 19 clusters.

Then, we list detailed information of these 19 clusters in Table 4, including cluster ID, size, percentage of the network, silhouette value, start-stop time, duration, mean year, and labels based on the LLR algorithm. Silhouette values of all 19 clusters are greater than 0.7, indicating that clusters are highly reliable and members have high internal consistency. The largest cluster is \#0 Chinese manufacturer composed of 361 nodes, which accounted for $15.51 \%$ of the whole network. Each of the seven largest clusters has over 100 members representing $64.12 \%$ of cited references of the entire network. We are particularly interested in the duration of one cluster. There are eight clusters whose durations exceed 10 years, including \#0 Chinese manufacturer, \#1 sustainable supply chain management, \#2 green supply chain management, \#3 sustainable supplier selection, \#5 and-trade regulation, \#6 closed-loop supply chain, \#9 supply chain management profession, and \#11 corporate sustainability strategies, of which cluster \#3 spans the longest period, lasting 16 years. In terms of activeness, we find nine clusters remaining active, including \#1 sustainable supply chain management, \#3 sustainable supplier selection, \#4 circular economy, \#5 and-trade regulation, \#8 blockchain technology, \#10 big data analytics, \#12 COVID-19 pandemic, \#15 best-worst method, and \#26 logistics performance, which can be considered as emerging trends of SSCM, except \#1. 
Table 4. Detailed information about the largest clusters.

\begin{tabular}{|c|c|c|c|c|c|c|c|c|}
\hline ID & Size & $\%$ & Silhouette & Start & Stop & Duration & Mean & Label (LLR) \\
\hline 0 & 361 & 15.51 & 0.738 & 2005 & 2019 & 15 & 2009 & Chinese manufacturer \\
\hline 1 & 244 & 10.49 & 0.816 & 2010 & 2020 & 11 & 2014 & sustainable supply chain management \\
\hline 2 & 230 & 9.88 & 0.77 & 2008 & 2019 & 12 & 2013 & green supply chain management \\
\hline 3 & 200 & 8.59 & 0.873 & 2005 & 2020 & 16 & 2013 & sustainable supplier selection \\
\hline 4 & 157 & 6.75 & 0.972 & 2013 & 2020 & 8 & 2017 & circular economy \\
\hline 5 & 151 & 6.49 & 0.945 & 2010 & 2020 & 11 & 2016 & and-trade regulation \\
\hline 6 & 149 & 6.40 & 0.854 & 2008 & 2019 & 12 & 2012 & closed-loop supply chain \\
\hline 7 & 91 & 3.91 & 0.976 & 2002 & 2009 & 8 & 2005 & sustainable production network \\
\hline 8 & 84 & 3.61 & 0.99 & 2015 & 2020 & 6 & 2018 & blockchain technology \\
\hline 9 & 68 & 2.92 & 0.949 & 2004 & 2014 & 11 & 2006 & supply chain management profession \\
\hline 10 & 57 & 2.45 & 0.948 & 2012 & 2020 & 9 & 2015 & big data analytics \\
\hline 11 & 55 & 2.36 & 0.966 & 2008 & 2018 & 11 & 2013 & corporate sustainability strategies \\
\hline 12 & 47 & 2.02 & 0.92 & 2013 & 2020 & 8 & 2016 & COVID-19 pandemic \\
\hline 13 & 46 & 1.98 & 0.928 & 2010 & 2018 & 9 & 2013 & supply chain resilience \\
\hline 14 & 33 & 1.42 & 0.938 & 2011 & 2019 & 9 & 2016 & green human resource management \\
\hline 15 & 31 & 1.33 & 0.989 & 2015 & 2020 & 6 & 2017 & best-worst method \\
\hline 16 & 15 & 0.64 & 0.994 & 2006 & 2010 & 5 & 2007 & logistics issue \\
\hline 21 & 10 & 0.43 & 0.997 & 2013 & 2017 & 5 & 2015 & energy efficiency \\
\hline 26 & 5 & 0.21 & 1 & 2017 & 2020 & 4 & 2018 & logistics performance \\
\hline
\end{tabular}

Taking size and activeness of clusters into consideration, this study mainly focuses on the following specialties: \#1 Sustainable supply chain management, \#3 Sustainable supplier selection, \#4 circular economy, \#5 and-trade regulation, and \#8 blockchain technology. By reading core publications that include highly cited references as knowledge base and representative citing articles as research fronts, we can understand these clusters in depth.

The cluster \#1, labeled by sustainable supply chain management, is the second largest cluster containing 244 members and with a range of a 11-year duration from 2010 to 2020. A study by Ahi and Searcy (2013) is identified as the most cited reference and also has the strongest burst strength in the cluster. Ahi and Searcy [31] proposed a concise and comprehensive definition of SSCM, which captured key characteristics of both supply chain management and business sustainability. They argued SSCM was the extension of GSCM. As the second most cited article, the study of [15] used the term SSCM in a broad sense, which included all the environmental or social research of supply chain management, such as GSCM. The most representative citing article for cluster \#1 is that of Sánchez-Flores [44] covering 36 cited articles in the cluster, which performed a systematic literature review about SSCM research in the context of emerging economies, and showed that when compared to developed countries, the research in emerging economies lagged and was still in its infancy. The study of Mardani [60], covering 33 cited article in the cluster, further presented a systematic review regarding applications of the structural equation modeling (SEM) in the evaluation of GSCM and SSCM.

The cluster \#3, labeled by sustainable supplier selection, is the fourth largest cluster across a 16-year period from 2005 to 2020, which is the longest period of time among all clusters. Supplier selection plays a crucial part in SSCM. This cluster focuses on how to select and evaluate suppliers to achieve "triple bottom line" benefits. There are several novel integrated approaches to sustainable supplier selection and evaluation operations. The study of [61] presented a novel integrated fuzzy PIPRECIA-interval Rough SAW model for green supplier selection. Chattopadhyay et al. [62] employed an integrated D-MARCOS method, which can address the uncertainty in the supplier selection process. Durmi [63] applied the Full Consistency method (FUCOM) to define the evaluation of criteria for sustainable supplier selection. The study of [64] combined FUCOM-Rough SAW approach for supplier selection. When it comes to research fronts, the top two citing articles to this cluster offer literature reviews of state-of-the-art studies concerning sustainable supplier selection [65,66]. Based on previous researches, Ecer and Pamucar [67], 
Hendiani et al. [68], and Kannan et al. [69] cited more than 20 members in cluster \#3 and proposed the integrated F-BWM and fuzzy CoCoSo'B multi-criteria model, the multi-stage hierarchical fuzzy index-based approach, and the hybrid approach combining the fuzzy best-worst method and the interval VIKOR technique, respectively.

The cluster \#4, labeled by circular economy, contains 157 references, with a silhouette value of 0.972 , which is considered a high value. The average year of all members in this cluster is 2017, with an eight-year duration (2013-2020). The most cited article in cluster \#4 is published by Genovese et al. who asserted that in view of an environmental point, integrating principles underlying circular economy into SSCM can provide potential enhancement [70]. The study of Geissdoerfer, with the strongest burst strength in the cluster, distinguished the terms circular economy and sustainability explicitly, therefore, clarifying their conceptual contours [71]. The most active citing article covering 37 papers is the paper of [72], which first researched circular economy in the leather industry context and found that financial facility played a vital role in the implementation of circular economy practices by using the best worst method.

The cluster \#5, labeled by and-trade regulation, has 151 members with a silhouette value of 0.945 . The label can be revised as cap-and-trade regulation through reviewing citing articles. Cap-and-trade regulation is a carbon policy aimed at combating global warming. The most representative article in cluster \#5 was published by Ghosh and Shah [73] who explored the influence of cost sharing contract on green supply chains. With regard to representative citing articles, some studies conducted supply chain researches under cap-and-trade regulation, such as channel coordination in a two-echelon sustainable supply chain [74,75], stochastic dual-channel supply chain [76], production and carbon emission reduction strategies [77], and low-carbon production [78]. Tang and Yang [79] analyzed the influence of power structure and financing mechanism on a low-carbon supply chain.

The cluster \#8, labeled by blockchain technology, has 84 members, with a silhouette value of 0.99 . As a distributed digital ledger technology, blockchain technology has completely overturned the traditional idea of centralized organization, and is expected to solve some problems of some global supply chain management problems due to the globalization of supply chains. The most cited article in cluster \#8 is the paper titled "Blockchain technology and its relationships to sustainable supply chain management" [17], which is also hot paper in the WoS Core Collection. This paper examined the potential application of blockchain technology to overcome some barriers of supply chain sustainability. The most citing article of this cluster is the study of Chang and Chen [80] who conducted a literature review of blockchain-based supply chain research and argued that the application of blockchain can facilitate distributed governance and process automation for supply chain operations. Kayikci et al. [81] applied blockchain technology into a food supply chain and proposed a blockchain-enabled food supply chain framework, which can resolve traceability and accountability problems and ensure transparency. The study of Orji et al. [82] and Ar et al. [83] evaluated the critical factor of blockchain adoption in freight logistics industry and the feasibility of blockchain in logistics industry.

\subsubsection{Bursts in the Network of Document Co-Citations}

In this section, we identify the top 20 references with the strongest citation bursts lasting more than five years between 2007 and 2021 (see Table 5), which can be considered as major milestones in the development and of evolution SSCM search [39].

From 2007 to 2021, the focus of these major milestones can be summarized as follows. (1) Literature review of SSCM or GSCM. Sarkis et al. [55] conducted an organizational theoretic literature review of GSCM, whereas Carter and Easton [84] conducted a systematic review of SSCM. Other papers provided reviews from various angles. For example, using the method of content analysis, Gold et al. [85] highlighted that supply-chain-wide collaboration can facilitate inter-organizational resources and, thus, maintain inter-firm competitive advantage. Seuring [86] reviewed modeling approaches used in SSCM research 
and founded multi-criteria decision-making, equilibrium models, and analytical hierarchy processes were dominant approaches. (2) Building a conceptual framework of SSCM or GSCM. Seuring and Muller [29], and Carter and Rogers [30] presented a framework of SSCM, respectively, whereas Sarkis [87] provided a framework of GSCM based on a boundaries and flows perspective. It is noteworthy that the study of Seuring and Muller [29] had the strongest burst value of 139.32. (3) Evaluation or process of supplier selection. The study of [88] has experienced the longest burst period of six years, which introduced a method combining grey system with rough set theory for the supplier selection. Based on fuzzy analytic network process, Buyukozkan and Cifci [89] developed a fuzzy multicriteria decision framework with incomplete information. These scholars [90], then, in 2012, proposed a hybrid fuzzy multiple criteria decision-making model for evaluating green suppliers, which integrated DEMATEL, ANP, and TOPSIS in a fuzzy context. (4) Other topics related to SSCM, such as corporate social responsibility [91], firm performance [92], and sustainable sourcing [93].

Table 5. Top 20 references with the strongest citation bursts.

\begin{tabular}{|c|c|c|c|c|c|c|}
\hline Author & Year & Source & Strength & Begin & End & 2007-2021 \\
\hline Seuring S & 2008 & J CLEAN PROD & 139.32 & 2009 & 2013 & 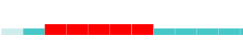 \\
\hline Carter CR & 2008 & INT J PHYS DISTR LOG & 79.65 & 2009 & 2013 & \\
\hline Seuring SA & 2008 & SUPPLY CHAIN MANAG & 26.48 & 2009 & 2013 & \\
\hline Pagell M & 2009 & J SUPPLY CHAIN MANAG & 60.89 & 2010 & 2014 & \\
\hline Bai C & 2010 & INT J PROD ECON & 37.2 & 2010 & 2015 & \\
\hline Gold S & 2010 & CORP SOC RESP ENV MA & 40.44 & 2011 & 2015 & \\
\hline Tate WL & 2010 & J SUPPLY CHAIN MANAG & 39.38 & 2011 & 2015 & \\
\hline Pagell M & 2010 & J SUPPLY CHAIN MANAG & 34.65 & 2011 & 2015 & \\
\hline Reuter C & 2010 & J SUPPLY CHAIN MANAG & 30.44 & 2011 & 2015 & \\
\hline Sarkis J & 2011 & INT J PROD ECON & 84.83 & 2012 & 2016 & \\
\hline Carter CR & 2011 & INT J PHYS DISTR LOG & 65.02 & 2012 & 2016 & \\
\hline Buyukozkan G & 2011 & COMPUT IND & 31.53 & 2012 & 2016 & \\
\hline Green KW & 2012 & SUPPLY CHAIN MANAG & 33.35 & 2013 & 2017 & \\
\hline Walker H & 2012 & SUPPLY CHAIN MANAG & 27.65 & 2013 & 2017 & \\
\hline Buyukozkan & 2012 & EXPERT SYST APPL & 23.48 & 2013 & 2017 & \\
\hline Sarkis J & 2012 & SUPPLY CHAIN MANAG & 23.1 & 2013 & 2017 & \\
\hline Miemczyk J & 2012 & SUPPLY CHAIN MANAG & 22.72 & 2013 & 2017 & \\
\hline Seuring S & 2013 & DECIS SUPPORT SYST & 56.72 & 2014 & 2018 & \\
\hline Ahi P & 2013 & J CLEAN PROD & 50.79 & 2014 & 2018 & \\
\hline Golicic SL & 2013 & J SUPPLY CHAIN MANAG & 32.08 & 2014 & 2018 & \\
\hline
\end{tabular}

\section{Conclusions and Discussion}

\subsection{Main Findings and Contributions}

SSCM has been attracting extensive attention from both practitioners and scholars. More and more firms realize the importance of the concept of sustainable development and implement SSCM practices in order to realize an organization's social, environmental, and economic goals. The significant increasing number of empirical and conceptual papers on SSCM topics indicates that SSCM research is getting more and more academic attention. However, there are limited bibliometric literature reviews on SSCM to help us gain a better understanding and overview of the evolution of this field. The main objective of this study is to visualize and conduct a systematic scientometric review on 9151 articles and reviews published from 2007 to 2021. Research techniques of co-author analysis, co-word analysis, and co-citation analysis are applied in this study to address three research questions: RQ1: What is the social structure of the SSCM field? RQ2: What is the conceptual structure of the SSCM field? RQ3: What is the intellectual structure of the SSCM field? We mainly focus important nodes with high frequency, high betweenness centrality, or high burst strength. We reveal social structure, conceptual structure, and intellectual structure, identify main concepts and research hotspots, and illuminate major specialties and emerging trends, which are 
valuable to the readers. We expect this paper will provide a big picture for researchers as well as practitioners. The main findings and contributions are as follows.

Firstly, based on the analysis of co-authorship network and their institutions network, the social structure of the SSCM field is revealed. The authors' group has not yet formed strong relationships of collaboration. Joseph Sarkis and Kannan Govindan are located in structural holes. The top five most productive scholars are Joseph Sarkis, Kannan Govindan, Minglang Tseng, Angappa Gunasekaran, and Charbel Jose Chiappetta Jabbour. The following authors have been bursting to present: Minglang Tseng, Syed Mithun Ali, Ming K Lim, Rakesh D Raut, Morteza Rastibarzoki, Sachin Kumar Mangla, and Wenyan Song who have burst durations no less than four years. As for institutions, University of Sheffield, University of Kent, University of Liverpool, University of Plymouth, University of Massachusetts Dartmouth, and Chalmers University of Technology have occupied crucial positions in the research network of SSCM research. Hong Kong Polytechnic University, Islamic Azad University, University of Southern Denmark, Dalian University of Technology, and University of Tehran are the top five most productive institutions. There are eight institutions that have been lasting for more than five years, including University of Bath, Arizona State University, Oregon State University, Griffith University, University of Padua, University of Strathclyde, Linkoping University, and University of Twente.

Secondly, based on the analysis of co-occurring keywords network, the conceptual structure of the SSCM field is revealed. The top five keywords with high count include sustainability, supply chain management, supply chain, sustainable development, and circular economy. The top five keywords with high betweenness centrality include supply chain, sustainable supply chain management, reverse logistics, strategy, and corporate social responsibility. The keywords with a burst period greater than five years include supply chain management, environmental management, social responsibility, transportation, eco-efficiency, logistics, strategy, and corporate sustainability. The top five strongest burst keywords include supply chain management, environmental management, social responsibility, transportation, and supplier management, which are research hotspots in their corresponding periods. The main concepts include sustainable supply chain management, green supply chain management, circular economy, corporate social responsibility, and reverse logistics. The research hotspots of the SSCM field currently are game theory and circular economy related researches.

Thirdly, based on the analysis of author, journal and document co-citation network, the intellectual structure of the SSCM field is revealed. The top five most highly cited authors are Stefan Seuring, Kannan Govindan, Craig R. Carter, Qinghua Zhu, and Joseph Sarkis. The leading researchers are Stefan Seuring, Kannan Govindan, Craig R. Carter, Qinghua Zhu, Joseph Sarkis, John Elkington, Stephan Vachon, Kathleen M. Eisenhardt, Ming-LangTseng, and Gülçin Büyüközkan. The top five productive journals include the Journal of Cleaner Production, Sustainability, International Journal of Production Economics, International Journal of Production Research, and Business Strategy and the Environment. The top five influential journals in SSCM research include Journal of Cleaner Production, International Journal of Production Economics, International Journal of Production Research, European Journal of Operational Research, and Supply Chain Management-An International Journal. The emerging trends have shifted away from Chinese manufacturer, green supply chain management (GSCM), closed-loop supply chain, green human resource management, corporate sustainability strategies, supply chain resilience, energy efficiency, supply chain management profession, logistics issue, and sustainable production network toward sustainable supplier selection, circular economy, cap-and-trade regulation, blockchain technology, big data analytics, COVID-19 pandemic, best-worst method, and logistics performance, which are likely to define the new research fronts in the field of SSCM research. Moreover, we also identify top 20 references with the strongest citation bursts lasting more than five years between 2007 and 2021, which can be considered as major milestones in the development and evolution of SSCM search. 


\subsection{Limitations and Future Researches}

Our papers have several limitations from the following aspects: databases, publication types, search terms, method, and citation manipulation. Firstly, the bibliometric dataset is retrieved from SCI-E and SSCI in the WoS Core Collection. Various results and conclusions may appear if the dataset is collected from other databases. Therefore, future research can retrieve data from other databases such as the Scopus database, which also includes comprehensive scientific data that is rigorously vetted and selected. Secondly, we delimit peer-reviewed articles and reviews in the English language, and exclude publications from other document types such as books or proceeding papers and other languages such as the Chinese language, which may result in incomplete records. Therefore, future research should cover more various publication types and other languages papers. Thirdly, while we ensure a rigorous retrieval process to construct a representative and comprehensive dataset, we also agree to the point that there may exist many articles, which lack the search term but still focus on the SSCM. Other search terms (e.g., green procurement, RSCM/GSCM, sustainable development and supply chain, sustainability in supply chain), which capture some constructs of SSCM, may also be used as search terms to cover a wider range of articles in future study. Fourthly, we mainly used the scientometric review approach to conduct a review. We can integrate the scientometric review approach with the traditional systematic review approach in future research. For example, we have revealed cluster \#8 blockchain technology, which has 84 members, with a silhouette value of 0.99 . We can identify representative cited references as the knowledge base and citing articles as research fronts of this cluster. Then we can use a traditional systematic review approach to consolidate these core publications. Therefore, we can get a comprehensive review and synthesis of extant SSCM studies with respect to theoretical perspectives, methodologies, gaps, and potential research avenues. In addition, citation manipulation may occur due to author self-citation, editor or journal self-citation requirements, which may influence the accuracy of co-citation analysis on SSCM research.

Though this study has its limitations, we remain confident that our systematic and comprehensive review offers valuable insights and guidance to readers including both researchers and practitioners in the field of SSCM. The findings presented in this paper provide insights regarding productive scholars and institutions, influential journals, main concepts, research hotspots, major specialties, and emerging trends for readers to better understand the state of the art of the SSCM field. Moreover, this study can facilitate SSCM practitioners to select appropriate institutions for SSCM consulting or cooperation. Based on our findings, we could suggest several related topics for future researches, which include sustainable supplier selection, circular economy, cap-and-trade regulation, blockchain technology, big data analytics, and the COVID-19 pandemic. These topics are emerging trends identified by the analysis of co-citation clusters. However, scholars pay more attention to the first three ones, rather than the rest. Specialties of blockchain technology, big data analytics, and the COVID-19 pandemic deserve more in-depth studies and further exploration. Several future research avenues or research questions are proposed to better understand these three themes.

(1) Blockchain technology. The application of blockchain technology to the supply chain can pose more challenges and opportunities for SSCM and has the potential to transform practices $[16,94]$. As a distributed database system, blockchain technology can be made use of to obtain competitive advantages and enhance market positions. There are several research questions that need to be further explored. RQ1: How does the introduction of blockchain technology significantly transform SSCM practices, such as advancing inventory management and replenishment, reducing the cost of supply chain transactions, or reducing the need for intermediaries? RQ2: How can blockchain technology be effectively implemented in complex supply chain networks? RQ3: What are the implementation challenges of the supply chain finance driven by blockchain technology, and how can they be overcome?

(2) Big data analytics. The big data processing technology can enable data integration [95], information feedback, and decision-making coordination in modern supply 
chains more and more effectively, which have become a possible source of competitive advantage. There are extensive research values and significance in the SSCM field within the context of big data. Considering the application of big data analytics, the following research questions need to be well answered. RQ1: How does the theory application and development of big data analytics challenge existing theory on SSCM? RQ2: What are the mechanism and path of the impact of big data analytics on SSCM? RQ3: How can big data analytics be applied for dynamic decision-making, evaluation of procurement risk, channel coordination, and strategic partnership in SSCM? RQ4: How can firms predict irresponsible supply chain issues, such as child labor, unethical behavior, and environmental pollution, through the information management practices based on big data analytics?

(3) COVID-19. With the increasing complexity of the supply chain across the world, the outbreak of the COVID-19 pandemic has disrupted global supply chains and caused chaotic situations in SSCM, which can pose survivability challenges to many enterprises [96]. Existing research has not yet conducted in-depth discussions about SSCM in the context of COVID-19 crisis. Thus, in future research, several research questions are worth exploring in depth. RQ1: To what extent and how the COVID-19 pandemic has influenced SSCM? RQ2: Whether SSCM companies better alleviate the effects of COVID-19 and gain profits in the post-COVID-19 economy? RQ3: How to optimize SSCM for resource allocation during epidemics/disasters?

Author Contributions: Conceptualization, M.Z.; methodology, W.W.; formal analysis, W.W. and Z.S.; data curation, Z.S.; writing—original draft preparation, Z.S.; writing—review and editing, M.Z. and W.W.; visualization, W.W. and Z.S.; project administration, M.Z.; funding acquisition, M.Z. All authors have read and agreed to the published version of the manuscript.

Funding: This work was funded by The Fundamental Research Funds for the Central Universities, grant number 2021JBWZD001.

Acknowledgments: All authors thank the editor and anonymous reviewers for their constructive comments and suggestions to improve the quality of this paper.

Conflicts of Interest: The authors declare no conflict of interest. The funders had no role in the design of the study; in the collection, analyses, or interpretation of data; in the writing of the manuscript, or in the decision to publish the results.

\section{References}

1. Alkahtani, M.; Omair, M.; Khalid, Q.S.; Hussain, G.; Ahmad, I.; Pruncu, C. A COVID-19 Supply Chain Management Strategy Based on Variable Production under Uncertain Environment Conditions. Int. J. Environ. Res. Public Health 2021, $18,1662$. [CrossRef]

2. Babagolzadeh, M.; Shrestha, A.; Abbasi, B.; Zhang, Y.H.; Woodhead, A.; Zhang, A.M. Sustainable cold supply chain management under demand uncertainty and carbon tax regulation. Transport. Res. Part D Transport. Environ. 2020, 80, 102245. [CrossRef]

3. Liu, J.; Xiao, T.J.; Tian, C.; Wang, H.M. Ordering and returns handling decisions and coordination in a supply chain with demand uncertainty. Int. Trans. Oper. Res. 2020, 27, 1033-1057. [CrossRef]

4. Meixell, M.J.; Luoma, P. Stakeholder pressure in sustainable supply chain management A systematic review. Int. J. Phys. Distrib. Logist. Manag. 2015, 45, 69-89. [CrossRef]

5. Roehrich, J.K.; Grosvold, J.; Hoejmose, S.U. Reputational risks and sustainable supply chain management Decision making under bounded rationality. Int. J. Oper. Prod. Manag. 2014, 34, 695-719. [CrossRef]

6. Wu, Z.F.; Zhai, S.J.; Hong, J.T.; Zhang, Y.B.; Shi, K.R. Building Sustainable Supply Chains for Organizations Based on QFD: A Case Study. Int. J. Environ. Res. Public Health 2018, 15, 2834. [CrossRef]

7. Mousa, S.K.; Othman, M. The impact of green human resource management practices on sustainable performance in healthcare organisations: A conceptual framework. J. Clean. Prod. 2020, 243, 118595. [CrossRef]

8. Pham, N.T.; Hoang, H.T.; Phan, Q.P.T. Green human resource management: A comprehensive review and future research agenda. Int. J. Manpow. 2020, 41, 845-878. [CrossRef]

9. Yu, W.T.; Chavez, R.; Feng, M.Y.; Wong, C.Y.; Fynes, B. Green human resource management and environmental cooperation: An ability-motivation-opportunity and contingency perspective. Int. J. Prod. Econ. 2020, 219, 224-235. [CrossRef]

10. Chen, P.K.; Ye, Y. Implementation strategy of environmental management systems in supply chains. Prod. Plan. Control. 2020, 1-12. [CrossRef]

11. Mungai, E.M.; Ndiritu, S.W.; Rajwani, T. Do voluntary environmental management systems improve environmental performance? Evidence from waste management by Kenyan firms. J. Clean. Prod. 2020, 265, 121636. [CrossRef] 
12. Luthra, S.; Govindan, K.; Kannan, D.; Mangla, S.K.; Garg, C.P. An integrated framework for sustainable supplier selection and evaluation in supply chains. J. Clean. Prod. 2017, 140, 1686-1698. [CrossRef]

13. Mohammed, A.; Harris, I.; Govindan, K. A hybrid MCDM-FMOO approach for sustainable supplier selection and order allocation. Int. J. Prod. Econ. 2019, 217, 171-184. [CrossRef]

14. Song, W.Y.; Xu, Z.T.; Liu, H.C. Developing sustainable supplier selection criteria for solar air-conditioner manufacturer: An integrated approach. Renew. Sustain. Energ. Rev. 2017, 79, 1461-1471. [CrossRef]

15. Pagell, M.; Shevchenko, A. Why Research in Sustainable Supply Chain Management Should Have no Future. J. Supply Chain Manag. 2014, 50, 44-55. [CrossRef]

16. Cole, R.; Stevenson, M.; Aitken, J. Blockchain technology: Implications for operations and supply chain management. Supply Chain Manag. 2019, 24, 469-483. [CrossRef]

17. Saberi, S.; Kouhizadeh, M.; Sarkis, J.; Shen, L.J. Blockchain technology and its relationships to sustainable supply chain management. Int. J. Prod. Res. 2019, 57, 2117-2135. [CrossRef]

18. Chen, Z.H.; Ming, X.G.; Zhou, T.T.; Chang, Y. Sustainable supplier selection for smart supply chain considering internal and external uncertainty: An integrated rough-fuzzy approach. Appl. Soft Comput. 2020, 87, 106004. [CrossRef]

19. Jain, N.; Singh, A.R. Sustainable supplier selection under must-be criteria through Fuzzy inference system. J. Clean. Prod. 2020, 248, 119275. [CrossRef]

20. Peng, J.J.; Tian, C.; Zhang, W.Y.; Zhang, S.; Wang, J.Q. An Integrated Multi-criteria Decision-making Framework For Sustainable Supplier Selection Under Picture Fuzzy Environment. Technol. Econ. Dev. Econ. 2020, 26, 573-598. [CrossRef]

21. Tirkolaee, E.B.; Mardani, A.; Dashtian, Z.; Soltani, M.; Weber, G.W. A novel hybrid method using fuzzy decision making and multi-objective programming for sustainable-reliable supplier selection in two-echelon supply chain design. J. Clean. Prod. 2020, 250, 119517. [CrossRef]

22. Hong, J.T.; Guo, P.J.; Chen, M.M.; Li, Y.T. The adoption of sustainable supply chain management and the role of organisational culture: A Chinese perspective. Int. J. Logist. Res. Appl. 2020, 1-25. [CrossRef]

23. Kumar, A.; Moktadir, M.A.; Khan, S.A.R.; Garza-Reyes, J.A.; Tyagi, M.; Kazancoglu, Y. Behavioral factors on the adoption of sustainable supply chain practices. Resour. Conserv. Recycl. 2020, 158, 104818. [CrossRef]

24. Rodthong, W.; Kuwornu, J.K.M.; Datta, A.; Anal, A.K.; Tsusaka, T.W. Factors Influencing the Intensity of Adoption of the Roundtable on Sustainable Palm Oil Practices by Smallholder Farmers in Thailand. Environ. Manag. 2020, 66, 377-394. [CrossRef]

25. Brammer, S.; He, H.W.; Mellahi, K. Corporate Social Responsibility, Employee Organizational Identification, and Creative Effort: The Moderating Impact of Corporate Ability. Group Organ. Manag. 2015, 40, 323-352. [CrossRef]

26. Hoejmose, S.; Brammer, S.; Millington, A. “Green" supply chain management: The role of trust and top management in B2B and B2C markets. Ind. Mark. Manag. 2012, 41, 609-620. [CrossRef]

27. Hoejmose, S.U.; Roehrich, J.K.; Grosvold, J. Is doing more doing better? The relationship between responsible supply chain management and corporate reputation. Ind. Mark. Manag. 2014, 43, 77-90. [CrossRef]

28. Brammer, S.; Walker, H. Sustainable procurement in the public sector: An international comparative study. Int. J. Oper. Prod. Manag. 2011, 31, 452-476. [CrossRef]

29. Seuring, S.; Muller, M. From a literature review to a conceptual framework for sustainable supply chain management. J. Clean. Prod. 2008, 16, 1699-1710. [CrossRef]

30. Carter, C.R.; Rogers, D.S. A framework of sustainable supply chain management: Moving toward new theory. Int. J. Phys. Distrib. Logist. Manag. 2008, 38, 360-387. [CrossRef]

31. Ahi, P.; Searcy, C. A comparative literature analysis of definitions for green and sustainable supply chain management. J. Clean. Prod. 2013, 52, 329-341. [CrossRef]

32. Grosvold, J.; Hoejmose, S.U.; Roehrich, J.K. Squaring the circle Management, measurement and performance of sustainability in supply chains. Supply Chain Manag. 2014, 19, 292-305. [CrossRef]

33. Paliwal, V.; Chandra, S.; Sharma, S. Blockchain Technology for Sustainable Supply Chain Management: A Systematic Literature Review and a Classification Framework. Sustainability 2020, 12, 7638. [CrossRef]

34. Koberg, E.; Longoni, A. A systematic review of sustainable supply chain management in global supply chains. J. Clean. Prod. 2019, 207, 1084-1098. [CrossRef]

35. Masoumi, S.M.; Kazemi, N.; Abdul-Rashid, S.H. Sustainable Supply Chain Management in the Automotive Industry: A Process-Oriented Review. Sustainability 2019, 11, 3945. [CrossRef]

36. Liu, Z.; Yin, Y.; Liu, W.; Dunford, M. Visualizing the intellectual structure and evolution of innovation systems research: A bibliometric analysis. Scientometrics 2015, 103, 135-158. [CrossRef]

37. Carter, C.R.; Washispack, S. Mapping the Path Forward for Sustainable Supply Chain Management: A Review of Reviews. J. Bus. Logist. 2018, 39, 242-247. [CrossRef]

38. Nimsai, S.; Yoopetch, C.; Lai, P. Mapping the Knowledge Base of Sustainable Supply Chain Management: A Bibliometric Literature Review. Sustainability 2020, 12, 7348. [CrossRef]

39. Chen, C. Science Mapping: A Systematic Review of the Literature. J. Data Inf. Sci. 2017, 2, 1-40. [CrossRef]

40. Chen, C.; Dubin, R.; Kim, M.C. Orphan drugs and rare diseases: A scientometric review (2000-2014). Expert Opin. Orphan Drugs 2014, 2, 709-724. [CrossRef] 
41. Chen, C.M.; Hu, Z.G.; Liu, S.B.; Tseng, H. Emerging trends in regenerative medicine: A scientometric analysis in CiteSpace. Expert Opin. Biol. Ther. 2012, 12, 593-608. [CrossRef]

42. Chen, C.M.; Song, M. Visualizing a field of research: A methodology of systematic scientometric reviews. PLoS ONE 2019, 14, e0223994. [CrossRef] [PubMed]

43. Ansari, Z.N.; Kant, R. A state-of-art literature review reflecting 15 years of focus on sustainable supply chain management. J. Clean. Prod. 2017, 142, 2524-2543. [CrossRef]

44. Sanchez-Flores, R.B.; Cruz-Sotelo, S.E.; Ojeda-Benitez, S.; Ramirez-Barreto, M.E. Sustainable Supply Chain Management-A Literature Review on Emerging Economies. Sustainability 2020, 12, 6972. [CrossRef]

45. Li, X.J.; Ma, E.; Qu, H.L. Knowledge mapping of hospitality research-A visual analysis using CiteSpace. Int. J. Hosp. Manag. 2017, 60, 77-93. [CrossRef]

46. Bouazzaoui, M.; Wu, H.J.; Roehrich, J.K.; Squire, B.; Roath, A.S. Justice in inter-organizational relationships: A literature review and future research agenda. Ind. Mark. Manag. 2020, 87, 128-137. [CrossRef]

47. Patel, A.B.; Desai, T.N. A systematic review and meta-analysis of recent developments in sustainable supply chain management. Int. J. Logist. Res. Appl. 2019, 22, 349-370. [CrossRef]

48. Wang, W.; Lu, C. Visualization analysis of big data research based on Citespace. Soft Comput. 2020, 24, 8173-8186. [CrossRef]

49. Svensson, G. Aspects of sustainable supply chain management (SSCM): Conceptual framework and empirical example. Supply Chain Manag. 2007, 12, 262-266. [CrossRef]

50. Geldermann, J.; Treitz, M.; Rentz, O. Towards sustainable production networks. Int. J. Prod. Res. 2007, 45, 4207-4224. [CrossRef]

51. Chen, C. A Glimpse of the First Eight Months of the COVID-19 Literature on Microsoft Academic Graph: Themes, Citation Contexts, and Uncertainties. Front. Res. Metr. Anal. 2020, 5, 1-15. [CrossRef]

52. Chen, C.M.; Dubin, R.; Kim, M.C. Emerging trends and new developments in regenerative medicine: A scientometric update (2000-2014). Expert Opin. Biol. Ther. 2014, 14, 1295-1317. [CrossRef] [PubMed]

53. Cobo, M.J.; Lopez-Herrera, A.G.; Herrera-Viedma, E.; Herrera, F. Science Mapping Software Tools: Review, Analysis, and Cooperative Study Among Tools. J. Am. Soc. Inf. Sci. Technol. 2011, 62, 1382-1402. [CrossRef]

54. Li, C.; Ji, X.H.; Luo, X.G. Visualizing Hotspots and Future Trends in Phytomining Research Through Scientometrics. Sustainability 2020, 12, 4593. [CrossRef]

55. Sarkis, J.; Zhu, Q.H.; Lai, K.H. An organizational theoretic review of green supply chain management literature. Int. J. Prod. Econ. 2011, 130, 1-15. [CrossRef]

56. Govindan, K.; Azevedo, S.G.; Carvalho, H.; Cruz-Machado, V. Impact of supply chain management practices on sustainability. J. Clean. Prod. 2014, 85, 212-225. [CrossRef]

57. Eisenhardt, K.M.; Graebner, M.E. Theory building from cases: Opportunities and challenges. Acad. Manag. J. 2007, 50, 25-32. [CrossRef]

58. Song, J.; Zhang, H.; Dong, W. A review of emerging trends in global PPP research: Analysis and visualization. Scientometrics 2016, 107, 1111-1147. [CrossRef]

59. Yang, R.; Wong, C.W.Y.; Miao, X. Analysis of the trend in the knowledge of environmental responsibility research. J. Clean. Prod. 2021, 278, 123402. [CrossRef]

60. Mardani, A.; Kannan, D.; Hooker, R.E.; Ozkul, S.; Alrasheedi, M.; Tirkolaee, E.B. Evaluation of green and sustainable supply chain management using structural equation modelling: A systematic review of the state of the art literature and recommendations for future research. J. Clean. Prod. 2020, 249, 119383. [CrossRef]

61. Ali, I.; Stevi, E.; Karamasa, C.; Puka, A. A Novel Integrated Fuzzy PIPRECIA-Interval Rough Saw Model: Green Supplier Selection. Decis. Mak. Appl. Manag. Eng. 2020, 3, 126-145.

62. Chattopadhyay, R.; Chakraborty, S.; Chakraborty, S. An integrated D-MARCOS method for supplier selection in an iron and steel industry. Decis. Mak. Appl. Manag. Eng. 2020, 3, 49-69. [CrossRef]

63. Durmi, E. The Evaluation of the Criteria for Sustainable Supplier Selection by Using the FUCOM Method. Oper. Res. Eng. Sci. Theory Appl. 2019, 2, 91-107. [CrossRef]

64. Durmić, E.; Stević, Ž.; Chatterjee, P.; Vasiljević, M.; Tomašević, M. Sustainable supplier selection using combined FUCOM-Rough SAW model. Rep. Mech. Eng. 2020, 1, 34-43. [CrossRef]

65. Zhang, L.-J.; Liu, R.; Liu, H.-C.; Shi, H. Green Supplier Evaluation and Selections: A State-of-the-Art Literature Review of Models, Methods, and Applications. Math. Probl. Eng. 2020, 2020, 1783421. [CrossRef]

66. Schramm, V.B.; Barros Cabral, L.P.; Schramm, F. Approaches for supporting sustainable supplier selection-A literature review. J. Clean. Prod. 2020, 273, 123089. [CrossRef]

67. Ecer, F.; Pamucar, D. Sustainable supplier selection: A novel integrated fuzzy best worst method (F-BWM) and fuzzy CoCoSo with Bonferroni (CoCoSo'B) multi-criteria model. J. Clean. Prod. 2020, 266, 121981. [CrossRef]

68. Hendiani, S.; Mahmoudi, A.; Liao, H. A multi-stage multi-criteria hierarchical decision-making approach for sustainable supplier selection. Appl. Soft Comput. 2020, 94, 106456. [CrossRef]

69. Kannan, D.; Mina, H.; Nosrati-Abarghooee, S.; Khosrojerdi, G. Sustainable circular supplier selection: A novel hybrid approach. Sci. Total Environ. 2020, 722, 137936. [CrossRef]

70. Genovese, A.; Acquaye, A.A.; Figueroa, A.; Koh, S.C.L. Sustainable supply chain management and the transition towards a circular economy: Evidence and some applications. Omega 2017, 66, 344-357. [CrossRef] 
71. Geissdoerfer, M.; Savaget, P.; Bocken, N.M.P.; Hultink, E.J. The Circular Economy A new sustainability paradigm? J. Clean. Prod. 2017, 143, 757-768. [CrossRef]

72. Moktadir, M.A.; Ahmadi, H.B.; Sultana, R.; Fatema Tuj, Z.; Liou, J.J.H.; Rezaei, J. Circular economy practices in the leather industry: A practical step towards sustainable development. J. Clean. Prod. 2020, 251, 119737. [CrossRef]

73. Ghosh, D.; Shah, J. Supply chain analysis under green sensitive consumer demand and cost sharing contract. Int. J. Prod. Econ. 2015, 164, 319-329. [CrossRef]

74. Qian, X.H.; Chan, F.T.S.; Zhang, J.H.; Yin, M.Q.; Zhang, Q.Y. Channel coordination of a two-echelon sustainable supply chain with a fair-minded retailer under cap-and-trade regulation. J. Clean. Prod. 2020, 244, 118715. [CrossRef]

75. Xu, J.T.; Chen, Y.Y.; Bai, Q.G. A two-echelon sustainable supply chain coordination under cap-and-trade regulation. J. Clean. Prod. 2016, 135, 42-56. [CrossRef]

76. Ghosh, S.K.; Seikh, M.R.; Chakrabortty, M. Analyzing a stochastic dual-channel supply chain under consumers' low carbon preferences and cap-and-trade regulation. Comput. Ind. Eng. 2020, 149, 106765. [CrossRef]

77. Wang, Z.R.; Brownlee, A.E.I.; Wu, Q.H. Production and joint emission reduction decisions based on two-way cost-sharing contract under cap-and-trade regulation. Comput. Ind. Eng. 2020, 146, 106549. [CrossRef]

78. Du, S.F.; Tang, W.Z.; Song, M. Low-carbon production with low-carbon premium in cap-and-trade regulation. J. Clean. Prod. 2016, 134, 652-662. [CrossRef]

79. Tang, R.H.; Yang, L. Impacts of financing mechanism and power structure on supply chains under cap-and-trade regulation. Transp. Res. Part E Logist. Transp. Rev. 2020, 139, 101957. [CrossRef]

80. Chang, S.C.E.; Chen, Y.C. When Blockchain Meets Supply Chain: A Systematic Literature Review on Current Development and Potential Applications. IEEE Access 2020, 8, 62478-62494. [CrossRef]

81. Kayikci, Y.; Subramanian, N.; Dora, M.; Bhatia, M.S. Food supply chain in the era of Industry 4.0: Blockchain technology implementation opportunities and impediments from the perspective of people, process, performance, and technology. Prod. Plan. Control 2020, 21, 1-21. [CrossRef]

82. Orji, I.J.; Kusi-Sarpong, S.; Huang, S.F.; Vazquez-Brust, D. Evaluating the factors that influence blockchain adoption in the freight logistics industry. Transp. Res. Part E Logist. Transp. Rev. 2020, 141, 102025. [CrossRef]

83. Ar, I.M.; Erol, I.; Peker, I.; Ozdemir, A.; Medeni, T.D.; Medeni, I.T. Evaluating the feasibility of blockchain in logistics operations: A decision framework. Expert Syst. Appl. 2020, 158, 113543. [CrossRef]

84. Carter, C.R.; Easton, P.L. Sustainable supply chain management: Evolution and future directions. Int. J. Phys. Distrib. Logist. Manag. 2011, 41, 46-62. [CrossRef]

85. Gold, S.; Seuring, S.; Beske, P. Sustainable Supply Chain Management and Inter-Organizational Resources: A Literature Review. Corp. Soc. Responsib. Environ. Manag. 2010, 17, 230-245. [CrossRef]

86. Seuring, S. A review of modeling approaches for sustainable supply chain management. Decis. Support. Syst. 2013, 54, 1513-1520. [CrossRef]

87. Sarkis, J. A boundaries and flows perspective of green supply chain management. Supply Chain Manag. 2012, 17, 202-216. [CrossRef]

88. Bai, C.; Sarkis, J. Integrating sustainability into supplier selection with grey system and rough set methodologies. Int. J. Prod. Econ. 2010, 124, 252-264. [CrossRef]

89. Buyukozkan, G.; Cifci, G. A novel fuzzy multi-criteria decision framework for sustainable supplier selection with incomplete information. Comput. Ind. 2011, 62, 164-174. [CrossRef]

90. Buyukozkan, G.; Cifci, G. A novel hybrid MCDM approach based on fuzzy DEMATEL, fuzzy ANP and fuzzy TOPSIS to evaluate green suppliers. Expert Syst. Appl. 2012, 39, 3000-3011. [CrossRef]

91. Tate, W.L.; Ellram, L.M.; Kirchoff, J.F. Corporate Social Responsibility Reports: A Thematic Analysis Related to Supply Chain Management. J. Supply Chain Manag. 2010, 46, 19-44. [CrossRef]

92. Golicic, S.L.; Smith, C.D. A Meta-Analysis of Environmentally Sustainable Supply Chain Management Practices and Firm Performance. J. Supply Chain Manag. 2013, 49, 78-95. [CrossRef]

93. Pagell, M.; Wu, Z.; Wasserman, M.E. Thinking Differently about Purchasing Portfolios. An Assessment of Sustainable Sourcing. J. Supply Chain Manag. 2010, 46, 57-73. [CrossRef]

94. Dutta, P.; Choi, T.M.; Somani, S.; Butala, R. Blockchain technology in supply chain operations: Applications, challenges and research opportunities. Transp. Res. Part E Logist. Transp. Rev. 2020, 142, 102067. [CrossRef]

95. Sanders, N.R.; Ganeshan, R. Big Data in Supply Chain Management. Prod. Oper. Manag. 2018, 27, 1745-1748. [CrossRef]

96. Farooq, M.U.; Hussain, A.; Masood, T.; Habib, M.S. Supply Chain Operations Management in Pandemics: A State-of-the-Art Review Inspired by COVID-19. Sustainability 2021, 13, 2504. [CrossRef] 